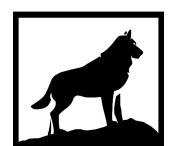

Michigan

Technological

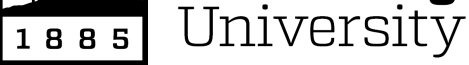

Michigan Technological University

Digital Commons @ Michigan Tech

2021

EFFECT OF SHORT-STORAGE HRGCs ON DRIVER DECISION BEHAVIOR AND SAFETY CONCERNS: REAL-WORLD ANALYSIS AND EXPERIMENTAL EVIDENCE

Anne Linja

Michigan Technological University, alinja@mtu.edu

Copyright 2021 Anne Linja

Recommended Citation

Linja, Anne, "EFFECT OF SHORT-STORAGE HRGCs ON DRIVER DECISION BEHAVIOR AND SAFETY CONCERNS: REAL-WORLD ANALYSIS AND EXPERIMENTAL EVIDENCE", Open Access Master's Thesis, Michigan Technological University, 2021.

https://doi.org/10.37099/mtu.dc.etdr/1188

Follow this and additional works at: https://digitalcommons.mtu.edu/etdr

Part of the Cognition and Perception Commons, and the Cognitive Psychology Commons 


\title{
EFFECT OF SHORT-STORAGE HRGCs ON DRIVER DECISION BEHAVIOR AND SAFETY CONCERNS: REAL-WORLD ANALYSIS AND \\ EXPERIMENTAL EVIDENCE
}

\author{
By \\ Anne Linja
}

\begin{abstract}
A THESIS
Submitted in partial fulfillment of the requirements for the degree of MASTER OF SCIENCE

In Applied Cognitive Science and Human Factors
\end{abstract}

MICHIGAN TECHNOLOGICAL UNIVERSITY

2020

(C) 2020 Anne Linja 
This thesis has been approved in partial fulfillment of the requirements for the Degree of MASTER OF SCIENCE in Applied Cognitive Science and Human Factors.

Department of Cognitive and Learning Sciences

Thesis Advisor: $\quad$ Dr. Elizabeth S. Veinott

Committee Member: Dr. Pasi Lautala

Committee Member: Dr. Kelly S. Steelman

Department Chair: Dr. Kelly S. Steelman 


\section{Table of Contents}

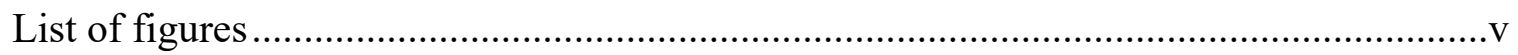

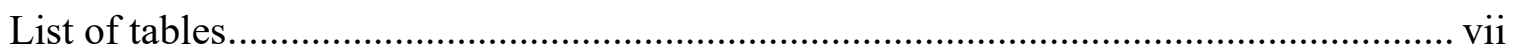

1 Introduction and Review of Literature on Factors Affecting Driver Behavior at Short-

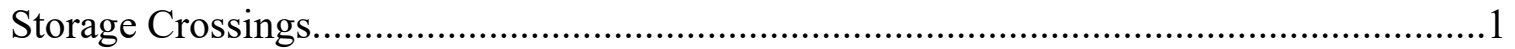

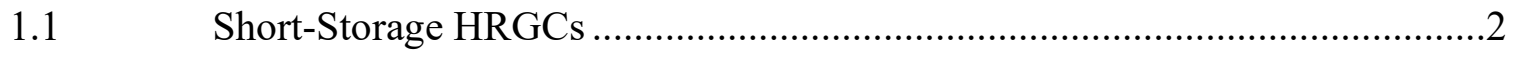

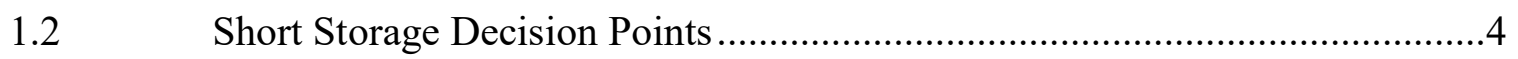

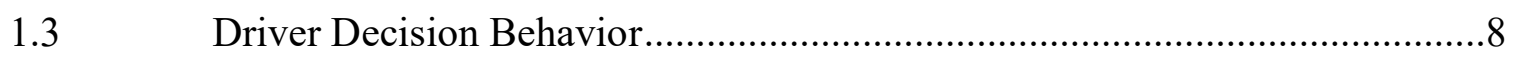

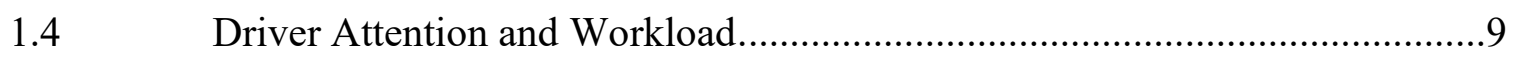

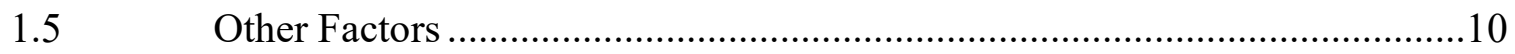

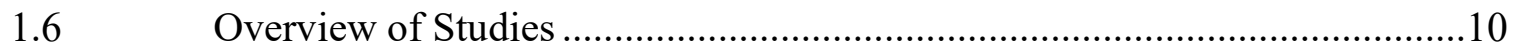

2 Study 1: A Real-World Analysis of Short-Storage vs. Non-Short-Storage using

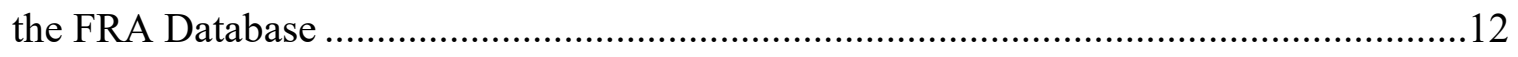

2.1 Federal Railroad Administration Database …………...................................12

2.1.1 Pre-Crash Behavior on Incident Frequency and Injury Severity .......13

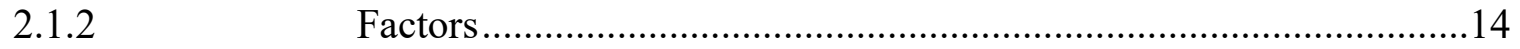

$2.2 \quad$ Introduction and Current Study ………….............................................

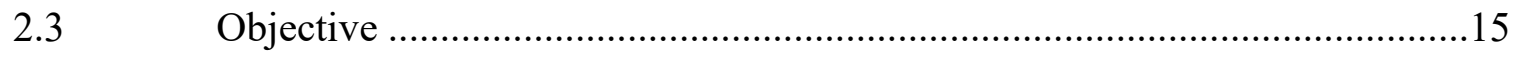

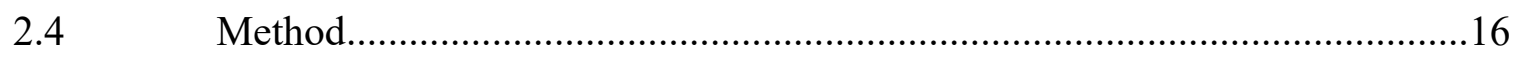

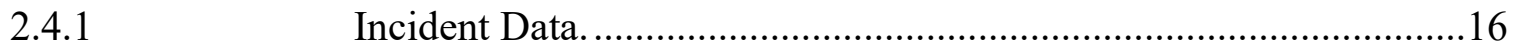

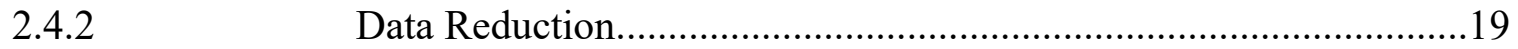

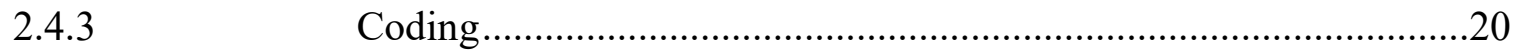

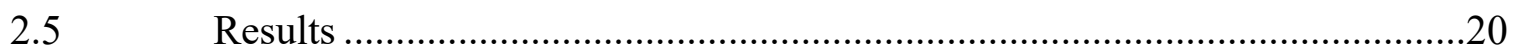

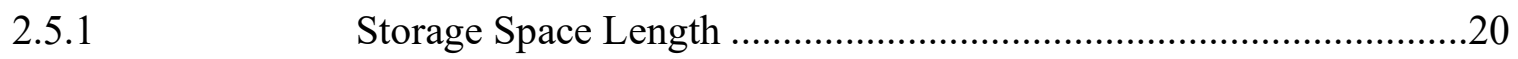

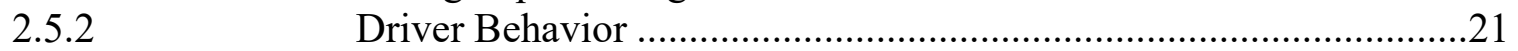

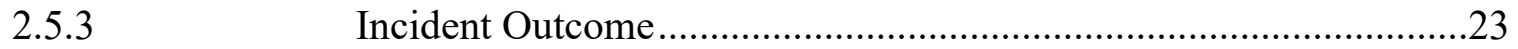

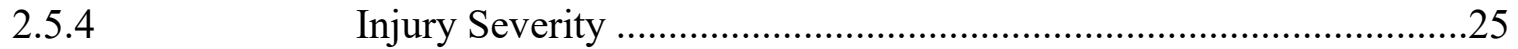

2.5.5 Demographics, Motor Vehicle Type, Protection Type ......................26

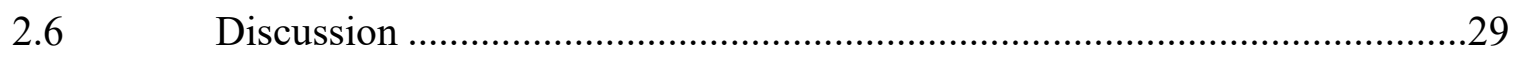

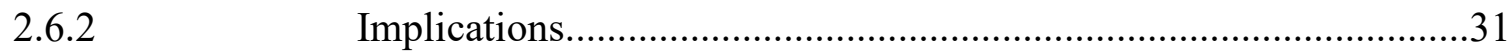

2.6.3 Limitations and Further Research ..................................................31

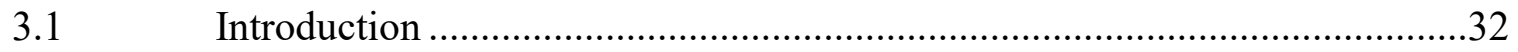

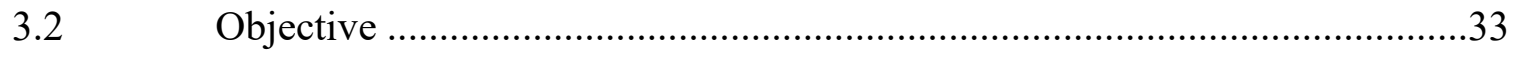




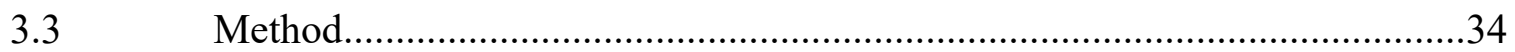

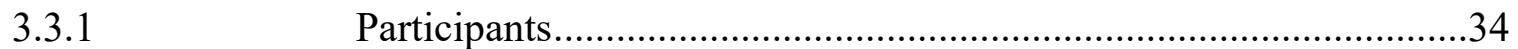

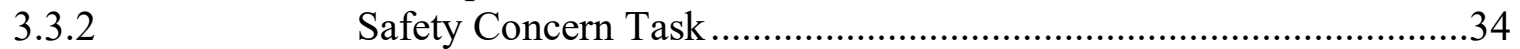

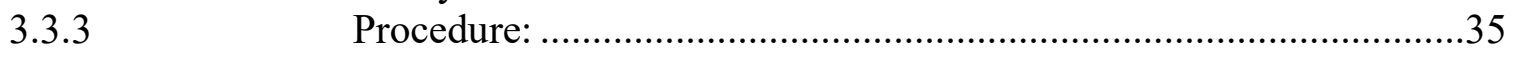

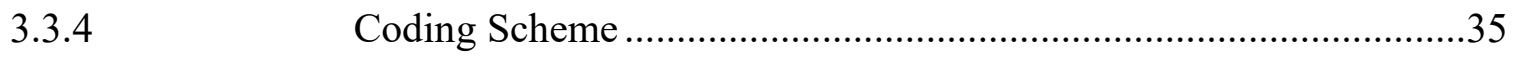

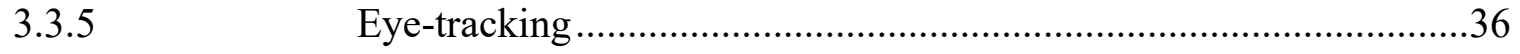

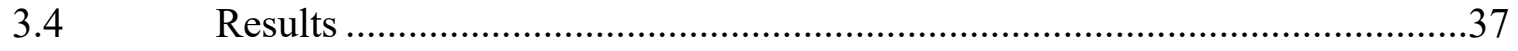

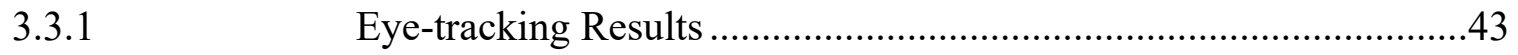

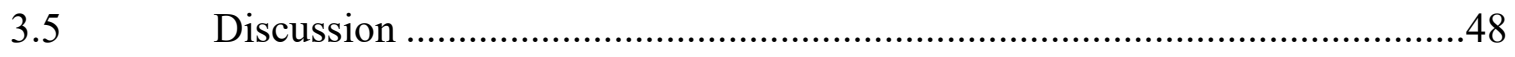

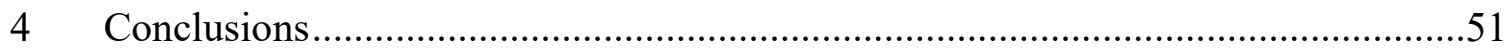

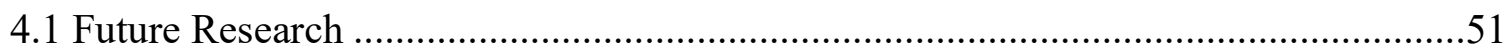

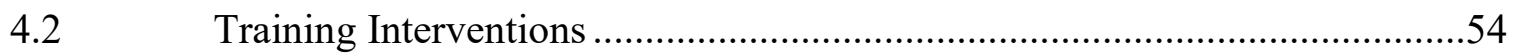

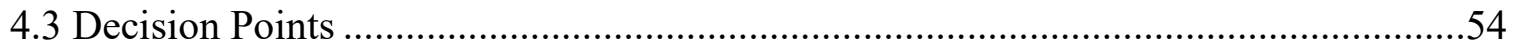

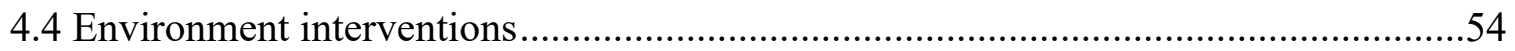

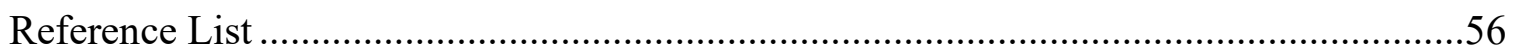

A1 Fields extracted for FRA Database study ......................................64

A2 Experiment 2 Questionnaire ……………………………………....67 


\section{List of figures}

$\begin{array}{lll}\text { Figure } 1.1 & \text { SS-Rail HRGC Diagram } & 7\end{array}$

Figure 1.2 SS-Rail HRGC 8

Figure $1.3 \quad$ Decision Points 9

Figure 1.4 Grade Crossing Advance Warning Sign 10

Figure 1.5 Short-Storage Sign 10

Figure 1.6 Crossbuck Sign 11

$\begin{array}{lll}\text { Figure 2.1 Input-Process-Output at HRGCs } & 17\end{array}$

$\begin{array}{lll}\text { Figure 2.2 Data Reduction } & 21\end{array}$

Figure 2.3 Impact - Who Struck Whom 24

Figure 2.4 Injury Severity by HRGC Type 26

Figure 2.5 HRGC Type by Age Groups 28

Figure 2.6 HRGC Type by Gender 29

Figure 2.7 Protection Type by HRGC Type 30

Figure 3.1 PEBL Safety Concern Task Screen 36

Figure 3.2 Areas of Interest in eye-tracking software 39

Figure 3.3 Average Number of Safety Concerns by HRGC Type 40

Figure 3.4 Effect of rail HRGC type and presence of obstruction on average number of safety concerns $\quad 41$

Figure 3.5 Average Severity of Safety Concerns by HRGC Type 42

Figure 3.6 Heat Map of One Participant's Fixations for Ten Seconds Prior to Annotation 
Figure 3.7 Fixations (with durations) From One Participant for Ten Seconds Prior to

Annotation

Figure 3.8 Average Gaze Duration by Driving Experience and HRGC Type 48

Figure 3.9 Average Fixation Count by Driving Experience and HRGC Type 49

Figure 3.10 Average Number of Fixations in AOI spaces by HRGC Type 50 


\section{List of tables}

Table 2.1. Variables defined in FRA database analysis 20

Table 2.2 HRGC Type by Driver Action 22

Table 2.3 HRGC Type by Driver Position 23

Table 2.4 Injury Severity by Circumstance - SS-Rail 25

Table 2.5 Injury Severity by Circumstance - Non-SS-Rail 25

Table 2.6 Storage Space Length 27

Table $2.7 \quad$ Vehicle Type 29

Table 3.1 Safety Concerns Coding Scheme with Examples 38

Table 3.2 Average Safety Concern Severity with Obstruction 42

Table 3.3 Average Safety Concern Severity by Safety Knowledge 43

Table $3.4 \quad$ Safety Concern Annotation Samples 44

Table 3.5 Distribution of Static Safety Concerns by Rail HRGC type 44

Table 3.6 Distribution of Dynamic Safety Concerns by Rail HRGC type 45 


\section{Acknowledgements}

I wish to express my sincere appreciation to my advisor, Dr. Elizabeth Veinott, for her relentless support with helping me to take my work to the next level. Your guidance and advice have helped me immeasurably. I have learned so much under your supervision and look forward to learning more from your expertise.

I would like to pay my special regards to the Gaming, Learning, Decision-Making lab, including Dr. Shane Mueller, and the rest of the group. Your reviews of the ongoing process have taken it to a level I could never have accomplished without you. Lamia and Tauseef, you are my partners in crime, and have made this process so much more fun for me.

This thesis was supported by the National University Rail (NURail) Center, a US DOTOST Tier 1 University Transportation Center. My sincere thanks to Dr. Pasi Lautala and David Nelson for helping me to learn everything I needed to know about this domain. Your support and expertise are appreciated.

I wish to acknowledge my fellow students who helped me with this project, specifically Kyle, Aliyah, Ashley, Josh, Stanton, and Via. Thanks for all your help, I appreciate it.

I am indebted to Dr. Kelly S. Steelman for her expertise on eye-tracking, salience, and human attention. Thank you for your input, which helped me see new angles in my research.

I would like to thank my family and friends for their never-ending support, especially my mom and my sisters. You have all helped me with long conversations and cheers when I needed it.

Last, but certainly not least, I would like to thank my husband Dave. You have always been my biggest fan and you have always had my back. You have pitched in more so I could have time to study. Your never-ending love and support are not only the reason I was able to do this, but also, the reason I am doing this. 


\section{Definitions}

For the purposes of this thesis, here are the definitions I will be using:

Active warning devices: dynamic, timely, oftentimes multi-modal warnings such as gates, flashing lights, and bells that are initiated by an approaching train

Driver: $\quad$ the motor vehicle operator (as opposed to the train driver)

Gender: $\quad$ the sex of the driver

Highway-Rail Grade Crossing: $\quad$ (HRGC) a location where a highway or road crosses one or more railroad tracks at grade. For this thesis, we will talk about public HRGCs only.

Passive warning devices: $\quad$ static signage and advance warnings

Preemption: normal operation of traffic signals is transferred to a special control mode; an interconnectedness of highway traffic signal and HRGC warning device operations

Short-Storage: a crossing where there is an intersection within 200 feet of the tracks, or preemption (normal operation of traffic signals is transferred to a special control mode)

Storage Space:the space between the railroad tracks and the intersection at a short-storage HRGC 


\section{List of abbreviations}

HRGC: Highway-Rail Grade Crossing

Non-SS-Rail: Any HRGC that is not considered to have a short-storage

SS-Rail: Short-storage HRGC 


\section{Abstract}

Vehicle-train collisions at highway-rail grade crossings (HRGCs) continue to be a safety concern, and despite improvements in warnings, many of these incidents are attributed to human error. In some cases, distractions other than railroad traffic, such as HRGCs with limited space between the railroad tracks and the highway intersection, may create additional cognitive burdens for drivers. We investigated the effect of HRGC type (short-storage vs. non-short storage) on driver attention and decision-making in two studies. In Study 1, we systematically analyzed 996 incidents from 2017-2019 from the Federal Railroad Administration's Safety database. Driver decision making and outcomes were different depending on HRGC type, with more train strikes in short storage incidents, as opposed to vehicle strikes. Study 2 was a controlled lab experiment in which drivers identified safety concerns in driving images. Drivers reported more safety concerns, and rated them more important in images of short-storage HRGCs than non-short storage HRGCs. This pattern did not depend on their rural or urban driving experience. Eye-tracking analysis found some differences in search behavior depending on the type of HRGC. This research contributes to a new area of research in rail safety, as studies comparing the two types of HRGCs have previously not been done. Interventions for non-short-storage HRGCs may not apply to short-storage HRGCs if it is found that drivers approach them differently. 


\section{Introduction and Review of Literature on Factors Affecting Driver Behavior at Short-Storage Crossings}

Each year, there are approximately 2,000 incidents at public Highway-Rail Grade Crossings (HRGC: a location where a public highway or road crosses one or more railroad tracks at grade; FRA), leaving more than 800 injuries and almost 300 fatalities (FRA, 2019). Almost 90\% are between motor vehicles and trains. Despite improvements in rail warnings, the number of incidents has remained steady in recent years.

There are over 125,000 public Highway-Rail Grade Crossings (HRGCs) in the U.S. Some crossings have active warning devices, with dynamic, timely, oftentimes multimodal warnings such as gates, flashing lights, and bells that are initiated by an approaching train. Some have passive warning devices, with static signage and advance warnings such as pavement markings, where drivers need to take notice, look for a train and act accordingly. Further, the type of traffic, speed, environment, etc. all shape driver behavior, decision-making, and even solutions applied to make HRGCs safer (Chan et al., 2010; Lerner, et al., 1990, Oh et al., 2006; Sanders et al., 1973, Tey et al., 2013). There is another element that contributes to possible safety issues at HRGCs, the type of HRGC. For example, a short-storage HRGC has an additional element, an intersection just after the tracks; this is yet another region to which a driver needs to attend.

Some improvements have been made to make crossings safer. For example, HRGCs with passive warning devices have been upgraded to crossings that have active warning devices. However, compliance towards advance warnings can be improved. For example, Meeker et al., (1997) performed a naturalistic study and measured compliance at a crossing with flashing lights only, then with an added barrier gate. They observed 60 drivers at a crossing. Compliance before the gate was installed was 33\% with the flashers only, and $62 \%$ after the gates were installed. This improvement resulted in improved driver behavior.

Human behavior accounts for $94 \%$ of all vehicle crashes (Brown, 2017); therefore, safety may be improved by understanding driver perception and attention. Despite improvements in rail warnings, the number of incidents due to human error has remained steady in recent years. Research to understand the human factors involved in vehicle-train incidents has attributed these errors to various factors. 
For example, the short-storage crossing mentioned briefly above, requires different attention than a non-short-storage crossing. The driver must pay attention to the railroad signage and a possible train, but also the intersection and its signage and other vehicles. The following discussion will further investigate drivers at HRGCs, specifically with regards to driver attention, decision-making, and behavior, and with the goal of examining the way short-storage HRGCs may play a role.

\subsection{Short-Storage HRGCs}

On October 25, 1995, in Fox Grove, IL, seven individuals lost their lives when the school bus they occupied was struck by a train. The bus was stopped at a red light, with its rear extended onto the tracks, causing a commuter train to strike it. The tragic incident illustrates the particular dangers at short-storage HRGCs.

The 125,000 HRGCs in the U.S. are made up of different HRGC configurations and warning systems (FRA, 2019). Improvements have been made to the domain as a whole. For example, warnings have been upgraded to make HRGCs more visible. However, there is one type of crossing that may need to be addressed separately - the short-storage (SS-Rail) highway-rail grade crossing. This limited storage space between the intersection and tracks might lead vehicles to be stopped on the tracks, and in the path of an arriving train as happened in the vehicle above. In contrast, non-short-storage crossings (Non-SS-Rail), which do not have an intersection following the track, allow vehicles to cross the tracks and proceed without stopping (Figure 1.1).

Figure 1.1

SS-Rail HRGC Diagram (left). The red rectangle represents the limited area of storage for queued vehicles. Non-SS-Rail HRGC (right).

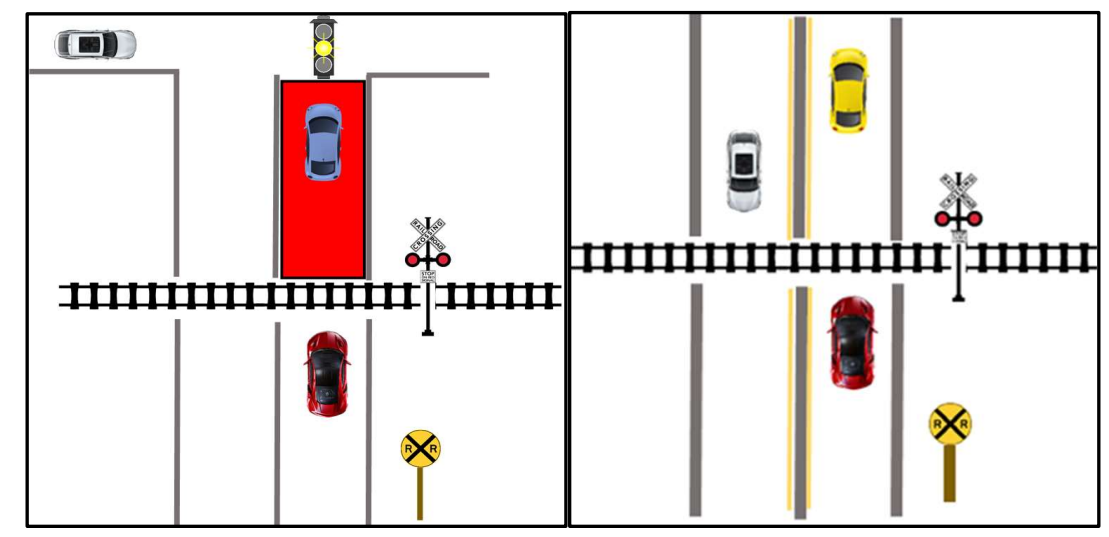


SS-Rail HRGCs have not been consistently defined. At the 2013 National Highway-Rail Grade Crossing Safety Training Conference, it was defined by CTC as:

"A short storage crossing is where the clear storage distance between the crossing and the highway intersection stop line is not sufficient to safely store a design vehicle (typically the longest legal truck combination)."

There are several other definitions in the literature. One definition comes from the HRGC Technical Group (2002), who stated an SS-Rail includes a roadway intersection immediately following (within about 100 feet) the tracks, resulting in a limited storage space for vehicles (Figure 1.2). For the purposes of this study, we are using the following definition:

"a crossing where there is an intersection within 200 feet of the tracks, or preemption (normal operation of traffic signals is transferred to a special control mode)"

Tustin et al. (1986) estimated that about $36 \%$ of HRGCs have a highway intersection within 75 feet, but little is known about the number and nature of incidents at these HRGCs. One of the current research goals is to assess this estimate by examining actual vehicle-train incidents in the Federal Railroad Administration database. If SS-Rail account for quite a few of the HRGCs, it is certainly worthwhile to investigate if drivers perceive them differently.

Figure 1.2

SS-Rail HRGC

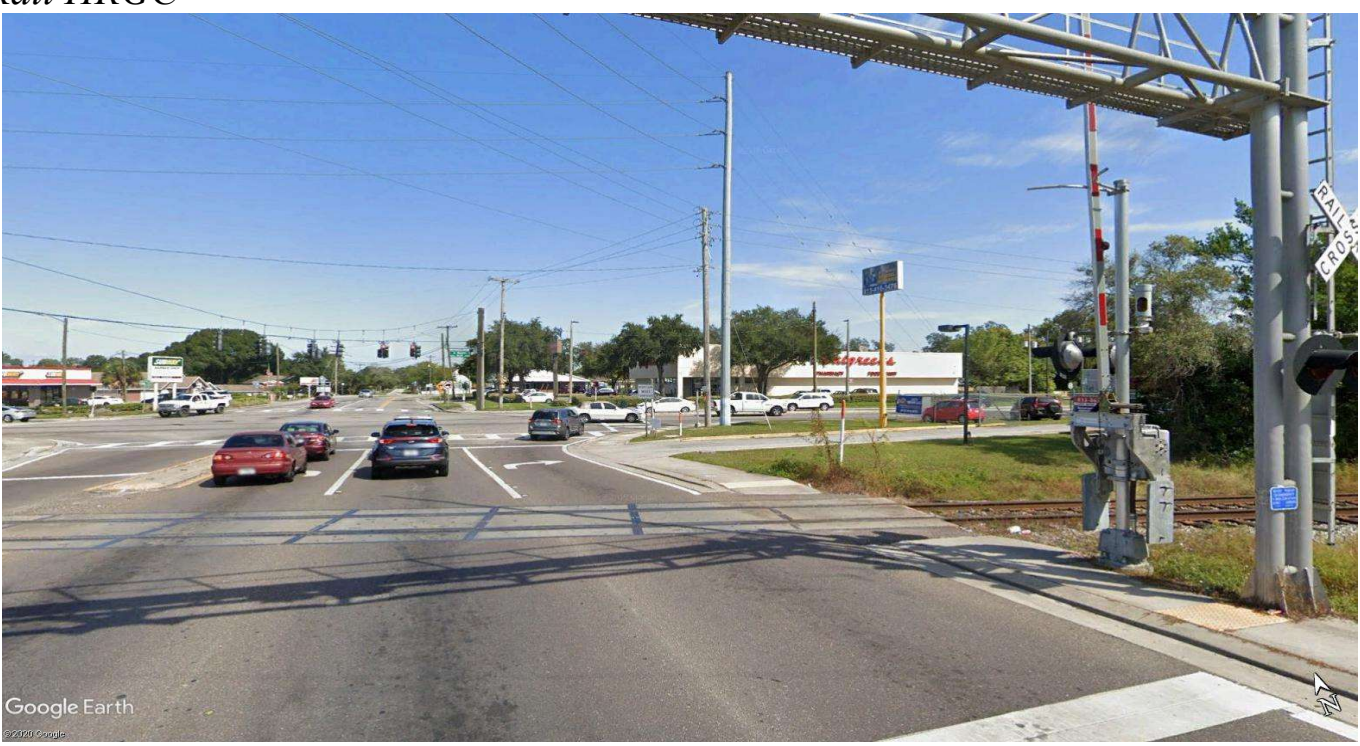

Map showing an SS-Rail HRGC. Google Earth, earth.google.com/web/. 
Drivers need to consider and manage a lot of information at SS HRGCs. An SS-Rail environment consists of a railroad track, where the driver must consider a potential train arrival. Additionally, there is an upcoming intersection, with lane configurations, potential traffic lights, other drivers with their own goals, and of course, the limited storage space. There might be businesses located at the intersection, with pedestrians trying to cross the street. These added factors create more cognitive challenges in SSRail HRGCs compared to Non-SS-Rail HRGCs.

The literature for SS-Rail is sparse and while a few papers mentioned the SS-Rail type of crossing, their focus has been on noting that it is a unique type of crossing which may affect safety. Campbell et al. (2015) suggested that SS-Rail is an issue that should be addressed by both domains - traffic engineers and railway experts; the two systems should work together. Improved traffic operations could be achieved by addressing traffic control, railroad preemption (where normal operation of traffic signals is transferred to a special control mode), railroad warning time (for the preemption), track clearance green (allowing vehicles to clear the tracks by going through a green light), and automatic gates. Guidance has been offered on traffic preemption strategies to clear SSRail storage space (Cho and Rilett, 2007; Marshall and Berg, 1997).

A report to the U.S. Department of Transportation (1997) suggested that state and local highway authorities should address SS-Rail HRGCs, making drivers familiar with the mechanics of this type of crossing, and running engineering studies to upgrade noninterconnected crossings with highways. Tustin et al. (1986) hypothesized that there is a higher rate of incidents at SS-Rail HRGCs, due to the limited storage space, and the need of the driver to consider not only crossing the tracks, but moving through the intersection. They also cited the fact that there are more distractions at SS-Rail HRGCs. Agreeing with many other researchers, they define the critical distance as "a function of the number of vehicles expected to be stopped by the intersection control".

\subsection{Short Storage Decision Points}

One way to examine the driver decision-making at SS-Rail HRGCs is to think about each crossing in terms of decision points (Figure 1.3). Drivers must make more decisions at SS-Rail HRGCs than Non-SS-Rail HRGCs. As a driver approaches a SS-Rail HRGC, there are four points at which they need to make decisions; these decisions vary depending on where they physically are in the HRGC traversal process. 
Figure 1.3

Decision Points
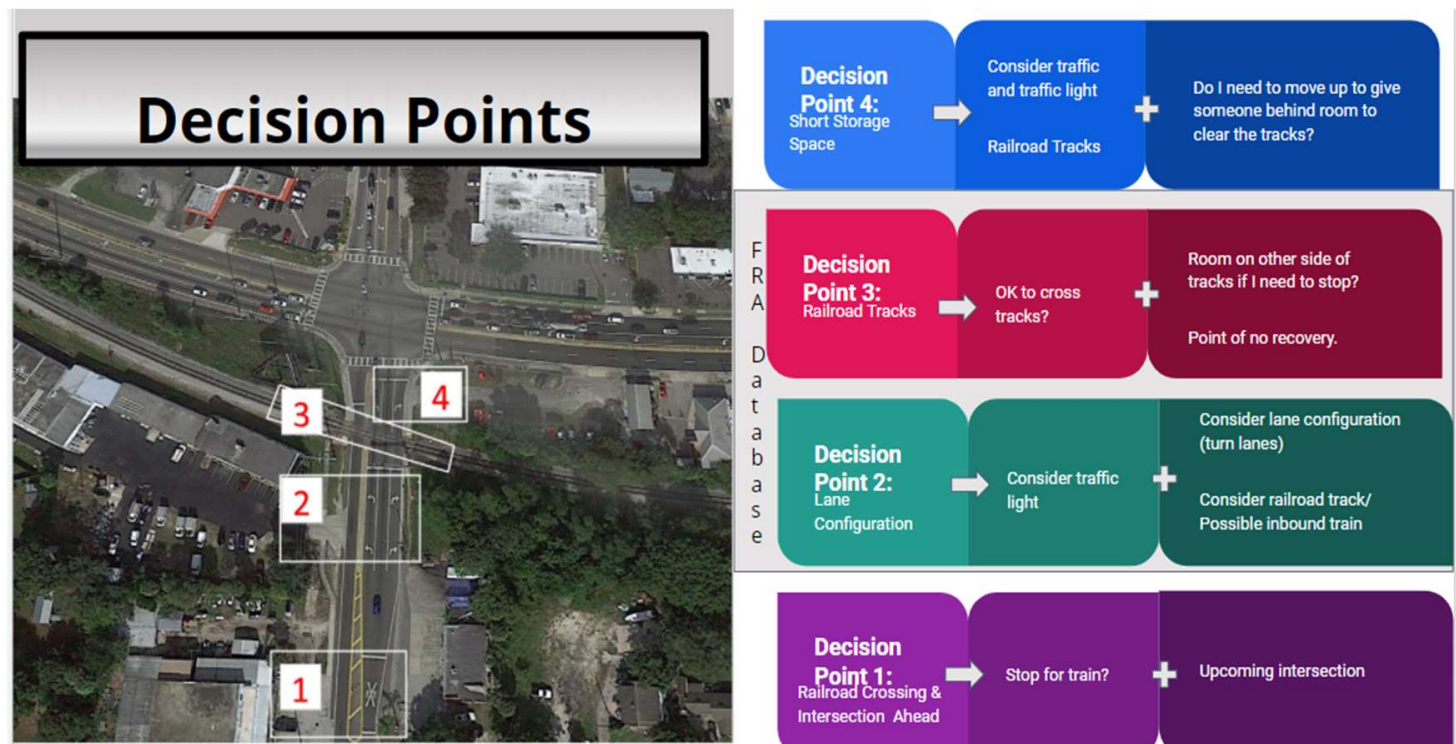

Map showing an SS-Rail HRGC. Google Earth, earth.google.com/web/.

\section{Decision Point 1, Railroad Crossing \& Intersection Ahead}

Drivers first see HRGC signage; this sign means there is a railroad ahead (Figure 1.4). In some cases, a second sign identifies a short-storage crossing (Figure 1.5). It alerts them to a HRGC and an intersection ahead. Drivers should scan for an arriving train and be aware of highway traffic. At this point they must be prepared for a potentially arriving train, and be prepared to slow down or stop accordingly. The driver should also be looking at the traffic light if it is visible, so they can get a feel for where it is in the greenyellow-red cycle.

\section{Figure 1.4}

Grade Crossing Advance Warning Sign

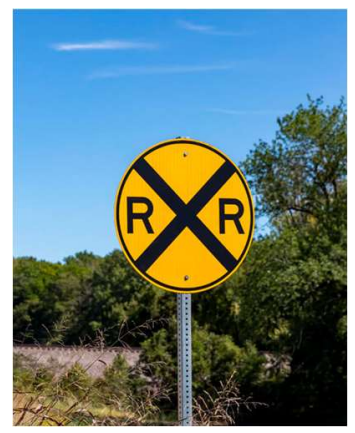

https:/driving-tests.org/road-signs/railroad-crossing-sign/ 
Figure 1.5

Short-Storage Railroad Sign

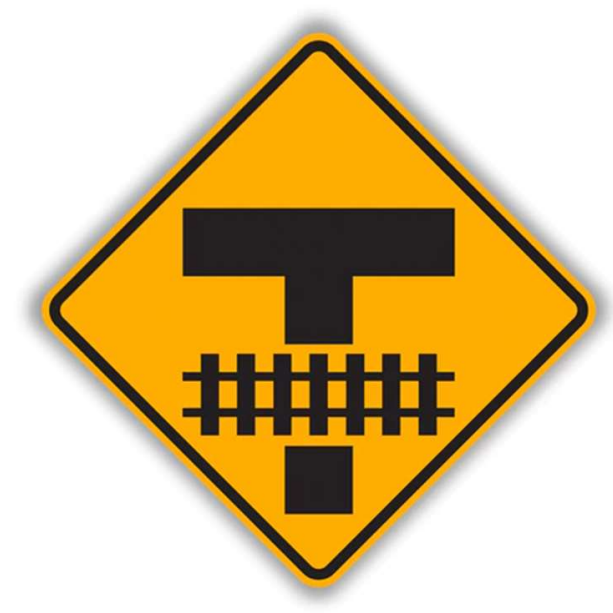

https://mutcd.fhwa.dot.gov/services/publications/fhwaop02084/images/w10_11.jpg

\section{Decision Point 2, Lane Configuration:}

Drivers need to take note of any lane configuration and guidance signage at this point. There may also be pavement markings indicating that a railroad crossing is ahead. As the driver approaches the tracks, they still need to consider the railroad tracks and a potentially arriving train. The driver needs to keep themselves apprised of the storage situation, and whether or not there will be room for them to stop after the tracks if necessary. Also, many times, since there is limited storage following the tracks, but before the intersection, the lane configuration for the intersection is identified before the tracks. The driver must make decisions on the proper lane for their vehicle while considering other lane-changing vehicles. At this time, the traffic light should continue to be observed so that they are better prepared to stop if necessary.

\section{Decision Point 3, Railroad Tracks:}

The crossbuck sign is located before the tracks (Figure 1.6). This has the potential to be a point of no recovery. Before crossing the tracks, the driver must make sure that there a train is not coming. In addition to deciding whether or not to cross the tracks, they need to decide if their vehicle will clear the tracks and if they will be able to proceed through the intersection. It is also possible that the light will have turned red while they were crossing the tracks; in this case, they need to make sure there's enough room for them to stop between the intersection and the tracks. 
Figure 1.6

Crossbuck Sign

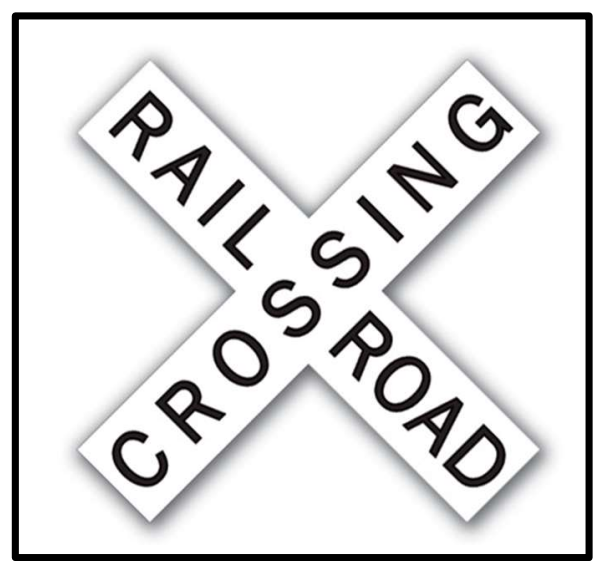

https://www.safetysupplywarehouse.com/CROSSBUCK_RAILROAD_CROSSING_Sig n_p/w14334.htm

\section{Decision Point 4, Short Storage Space:}

At this point, the driver has cleared the tracks. However, they still need to consider the traffic light and other vehicles. Also, it is possible that a vehicle behind them has not cleared the tracks, and the driver may need to move forward to give the vehicle behind them space to clear the tracks.

In 2019, across the U.S. there was an average of six vehicle-train incidents every day. The incidents averaged a fatality and two injuries daily. However, we do not know how many of these are attributed to SS-Rail HRGCs. To the extent that injuries are associated with SS-Rail HRGCs, then understanding the driver decision behavior at these types of crossing could lead to suggestions for improving safety at them.

Incidents at SS-Rail HRGCs are unique because the driver must consider the typical train factors (e.g., Is there a train coming? Do I need to stop before crossing the tracks?) and also the typical intersection factors (e.g., Is the traffic light turning yellow? What is the lane configuration? Which lane leads to my destination?). In addition to the train factors and the intersection factors, there are factors that make it a unique HRGC, such as whether or not there is sufficient storage space between the tracks and the intersection if the driver decides to cross the tracks. Perhaps traffic is moving, and there is plenty of storage space, but if the light turns yellow and the leading vehicle stops, suddenly a vehicle behind them is on the tracks with no way to move out of the way of an arriving train. In contrast, Non-SS-Rails HRGCs, which do not have an intersection following the track, allow vehicles to cross the tracks and proceed without stopping. 


\subsection{Driver Decision Behavior}

Most of the previous research has focused on compliance, familiarity, risk, and the critical decisions drivers make at HRGCs. For example, when a driver encounters a crossing, they make decisions on whether or not they will comply with the warnings. They decide whether or not to cross the tracks (Richards and Heathington, 1990), even if a train is visible on the horizon. These decisions lead to one of two options: safely crossing the tracks, or potential for being involved in an incident, These decisions can depend on how familiar they are with their environment.

Familiarity plays a role in driver behavior. A driver might traverse the same roads to work every day, and hardly ever encounter a train. However, if they go to work one hour later one day, they may not be familiar with the daily train that crosses at that time. They may just try to cross because they see the consequences of noncompliance as benign, due to their ability to cross every other day without event. When a driver is on a road containing an HRGC, and that road is familiar to them, their schema may inform them that trains on this road are rare. Babic et al. (2017) found that perception of signs declines when driving in a familiar environment. Therefore, the consequences of noncompliance in this situation are not seen as highly likely.

According to Lenne et al. (2011), drivers fall into two broad classes: those that intentionally cross on their own judgment, and those that make unintentional errors due to their unawareness of the situation. For those drivers who make intentional errors, such as risk-seekers (Witte and Donohue, 2000), deciding not to comply can lead to severe consequences. However, drivers can also have unintentional errors. This may be attributed to decision-making, but it also may be that people are not paying attention to the appropriate information.

Lautala et al. (2018) analyzed driver's looking behavior from driver videos at HRGCs using the Second Strategic Highway Research Program (SHRP2) Naturalistic Driving Study (NDS). They found that most drivers did not visually scan for trains or start braking early enough for a potential train. They also conducted a simulator study and found a similar result (Landry et al., 2019). If a driver does not scan properly, they might not see that there's a train coming. One question out of this research is whether or not they are noticing it, or whether they are noticing it and discounting it. 


\subsection{Driver Attention and Workload}

Attention research can inform the challenges at SS-Rail in several different ways. One way is awareness, another is inattention. Inattention, or poor distribution of attentional resources while driving can also lead to poor hazard perception at railroads, and also more casualties (Beanland et al., 2013; Metz et al., 2011). As a matter of fact, Zhao and Khattak (2018) found that inattentive drivers increased the possibility of suffering an injury in a crash by $9.7-14.6 \%$. Some researchers have found that inattention contributes to more incidences with younger drivers (Underwood, 2007; Zhao and Khattak, 2017).

Endsley (1995) calls situation awareness the perception of the environment, the comprehension of the environmental element's meaning, and the projection of the environmental element's future status. Experienced drivers have a more refined situation awareness compared to novices. Experienced drivers showed more concept relationship connectedness, whereas novice drivers had fewer concepts and the interconnectedness was less efficient (Salmon et al., 2013). Distractions have also led to poorer situation awareness; texting has been shown to lead to lower situation awareness, and longer braking times (Young et al., 2018).

Courage et al., (2000) found that faster speeds, narrow lanes and curved roads increased inattention. If this is the case, it is possible that more complicated HRGCs can increase inattention, due to additional demands.

Regan et al. (2011) developed a taxonomy of driver inattention to distinguish between different types of driver inattention. Among them was "driving-related" inattention (attention split between driving-related tasks). If a driver is encountering an HRGC, their attention is generally directed towards the railroad. However, presented with an HRGC followed immediately by an intersection, the driver's attention needs to be split between the railroad and the intersection. Hoel et al. (2010) called this "attentional competition". Researchers have recognized that both aspects (the railroad and the intersection) are equally critical for safety, and need to be managed with the same priority level.

Another facet of attention is mental-underload (Young and Stanton, 2002). Some HRGCs with passive warning devices (e.g., pavements markings, signs) have less compliance than HRGCs with active warning devices (e.g., gates, flashing lights). One must also consider that many rural crossings, with low vehicular traffic and low presence of trains likely have passive warning devices. A driver encountering one of these crossings might find themselves mentally-underloaded, with few traffic objects to which their attention should be paid. 
An additional attentional shortfall that drivers may encounter is change blindness. For example, in the case of a railroad track immediately followed by an intersection, a driver may look towards the intersection, then direct their attention towards the tracks to check for a train. When they look back at the intersection, the light may have changed its color, but change blindness blocks their ability to notice this change. Fortunately, Galpin et al., (2009) found that drivers noticed more relevant objects that were changed, than irrelevant objects. Furthermore, Rensink et al., (2000) found that focused attention can overcome this human shortfall.

\subsection{Other Factors}

There are other ways we can look at intentional vs unintentional driving errors. Additional factors include perception, environment, and personality characteristics. For instance, different textures and delineation can create different visual perceptions (Catherine et al., 2000). Imagine a short-storage HRGC, where a railroad crossing is immediately followed by an intersection. A driver might see a semi-truck in the space between the tracks and the intersection, and consider the space full. Another driver might see a couple of small, economy vehicles, and think there is room for their vehicle in the storage space. The semi-truck and the vehicles might have the same total length, but perceptually, the driver's vision is degraded (Leibowitz, 1985).

There's a lot of different explanations for intentional vs unintentional driving errors (noticing things and discounting them vs not noticing.) Those could involve mindwandering (Lerner et al., 2015), distraction, change blindness, or risk-taking.

Other factors such as environment can play a role in unsafe outcomes at HRGCs (Salim, 2018). For example, several researchers have found that obstruction plays a role in railroad safety (Pennetti et al., 2019; Ward and Wilde, 1996). An obstructed view of the train tracks can take much needed attention away from the intersection portion of an SSRail HRGC. Of the HRGCs used in the present study, $95 \%$ of them had an obstructed view for drivers coming from at least one of the four cardinal directions.

\subsection{Overview of Thesis Studies}

In the previous research, we have seen that driver's do not scan as we might expect, nor do they notice what we might expect. We do not know the extent of SS-Rail's account for incidents, nor do we know how SS-Rail attention, decision-making and behavior differ from Non-SS-Rail's. 
Therefore, the present studies aim to fill the gap by comparing driver decision behavior between SS-Rail HRGCs and Non-SS-Rail HRGCs. It is hoped that this initial research will provide a base for understanding driver attention and decision behavior at SS-Rail HRGCs. If it is found that driver's attention differs when comparing SS-Rail to Non-SSRail, can we be sure that current interventions for Non-SS-Rail are equally efficient at SS-Rail? If decision behaviors are different at SS-Rail, what are the effective ones? This may allow future researchers to examine how signage and other railroad interventions affect SS-Rail decisions and behavior.

The first study will analyze the Federal Railroad Administration Accident/Incident database to analyze how drivers behaved during incidents. The second study is a lab experiment to capture and compare the safety concerns college-age drivers notice SS-Rail and Non-SS-Rail HRGCs. 


\section{Study 1: A Real-World Analysis of Short-Storage vs. Non-Short-Storage using the FRA Database}

Safety at highway-rail grade crossings remains a concern (Read et al., 2016). Injuries and fatalities continue to occur despite improvements to infrastructure, signage, and driver training programs (Agrawal et al., 2017; McKenna and Crick, 1994; Unverricht et al., 2019). In the history of railroad safety improvements, engineers sometimes address one crossing at a time by running an engineering study, and making improvements to make the crossing safer. However, this is a reactive approach. Another way to understand what is happening is to analyze long-term real-world data. One might find patterns of unsafe driver behavior and use that to make crossings safer.

One method to run a real-world study in order to understand the safety issue is to use the Federal Railroad Administration (FRA) database, which has a wealth of accident/incident information.

Note that although the FRA uses the term motorist to refer to the drivers of the motor vehicles, consistent with other literature, we will be using the term driver.

\subsection{Federal Railroad Administration Database}

The FRA Office of Safety Analysis Website is a repository of safety information (accidents and incidents) available to the public (https://cms8.fra.dot.gov/accident-andincident-reporting/overview-reports/accident-data-reported-railroads). The incident form is filled out by railroad personnel any time there is an impact between a train and a highway-user. The database is used to document (reactive) each highway-rail incident, so that the FRA can identify dangerous trends, and develop hazard elimination and risk reduction programs to prevent injuries and accidents (proactive).

For the purposes of this study, we examined portions of the FRA database (and links to forms) related to vehicle-train incidents. There are four sources for information on the incidents on the FRA site. All of the data was merged into one file with the Accident/Incident ID as the unique identifier. Following is a description of each form.

- The HRGC Accident/Incident Report form contains information on the crossing at which the incident occurred, the highway user involved, the rail equipment involved, temperature, visibility, warnings at the crossing, driver demographic information, casualties, and a narrative description. This form is filled out if there is any impact between railroad on-track equipment and a highway user at an HRGC site (FRA Guide for Preparing Accident/Incident Reports).

- If a highway-rail grade crossing accident/incident results in a reportable casualty, the railroad must also file a Railroad Injury and Illness Summary. This form requests more specific information on any casualty. 
- The Inventory Report has information on the location and classification of the crossing, railroad information, highway or pathway traffic control device information, physical characteristics of the crossing, and public highway information.

- The online data grids offer summary information that is exportable.

Many researchers have used the FRA database extensively to examine the relative importance of many different factors on the frequency of incidents and accidents, as well as injury severity (Muhire et al., 2017; Raub, 2009; Yeh et al., 2012). These studies have focused on driver characteristics (e.g., age, gender), driver pre-crash behavior (e.g., trying to beat the train) and crossing signals and signage (e.g., active/passive protection) on the accident frequency and injury severity.

These studies have also found that age and gender affect frequency and injury severity. Specific demographic groups, such as females and older drivers, have also been shown to have a higher level of injury severity (Hao and Daniel, 2014; Raub, 2009). They also found that obstruction had an impact on the severity of injuries (Eluru et al., 2012). Injury severity has also been found to be higher at HRGCs with passive warning devices (Liu, et al., 2015).

\subsubsection{Pre-Crash Behavior on Incident Frequency and Injury Severity}

Pre-crash behavior can forecast a driver's ability to navigate an HRGC safely. Warning compliance is one behavior over which drivers have control (Cooper and Ragland, 2008; Liu and Khattak, 2017; Millegan et al., 2010). Berg et al., (1982) found that credibility and expectancy played a role in pre-crash behavior; adding flashing lights increased credibility, which led to better compliance, which led to safer crossings.

Another aspect that can affect pre-crash behavior is stopping sight distance, which is the sum of the distance traveled during a driver's brake reaction time (Indiana.gov, 2011). The document also states that 2.5 seconds is the brake reaction time (Ogden and Cooper, 2019). If there is an obstructed view of an arriving train at an HRGC, this must be considered when designing the crossing. Counterintuitively, Haleem and Gan (2015) found that unobstructed crossings led to an increase in injury likelihood. They found that drivers slowed down more at obstructed crossings. 


\subsubsection{Factors}

Researchers have found that many factors affect the outcome of an incident (Horrey, 2015; Lenne et al., 2011; Liu et al., 2015; McDonald et al., 2015). Using a logit regression, Haleem and Gan (2015) examined a variety of factors, including distance to a highway intersection, on injury severity in the FRA database. They found that highway intersections within 75 feet from the railroad tracks resulted in lower likelihood of injury than those crossings with longer distances. This is possibly because a closer intersection was paid more attention than an intersection that was further away from the HRGC.

There has been research on FRA incident outcomes depending whether the train struck the vehicle or vice versa. In a study comparing different types of warnings and collision rates, it is no surprise that Raub (2009) found that a train striking a vehicle is more likely to cause a fatality.

In Figure 2.1, the variables described above have been put into a conceptual model to organize and understand the current findings.

Figure 2.1

Input-Process-Output at HRGCs

\section{Input}

Person

- Gender

- Age

Environment

- Obstruction

Type of crossing

\section{Process}

Pre-crash

behavior
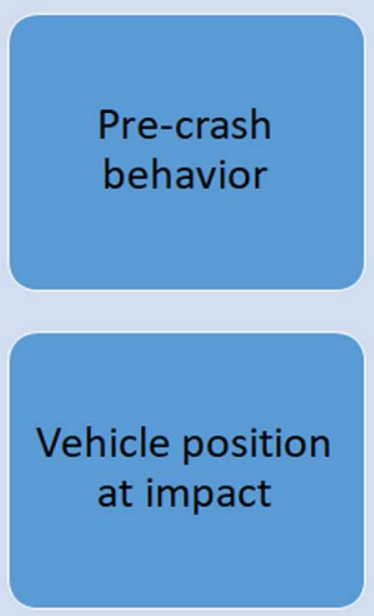

\section{Outcome}

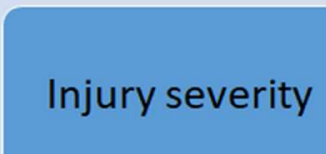

Frequency of incidents

Vehicle strike train/Train strike vehicle 


\subsection{Introduction and Current Study}

To our knowledge, different types of crossings, such as SS-Rail vs Non-SS-Rail, have not been the subject of railway research. This research will combine several sources of data to study whether or not there are differences in the vehicle-train incidents for two crossing types of SS-Rail HRGCs versus Non-SS-Rail HRCGs by evaluating Input, Process, and Output (Figure 2.1).

We will examine pre-crash behaviors by studying cognitive processes, demographics, environment, and driver decisions. This research may be used to give insight into possible differences between the types of crossings, and also to develop possible interventions in railway safety efforts.

The FRA database allows us to examine pre-crash behavior at Decision Points $2 \& 3$ previously mentioned in Chapter 1 . Decision Point 2 is the area just before the tracks where the driver will need to consider lane configurations and rail/traffic signage. Decision Point 3 is the railroad tracks themselves, where the driver will need to consider whether or not it is appropriate to try to cross the tracks. With the FRA database, we are able to learn what the driver was doing just prior to crossing the tracks, and their position as a train approached. One limitation is that we do not know how drivers acted when there a train was not approaching, as each data point analyzed results in an incident. However, the data we have allows us to see if the driver slowed down, stopped, tried to beat the train, etc.

This study sought to understand how the following related to SS-Rail HRGCs:

- Driver characteristics such as age and gender

- Driving behaviors such as speed and stopping location

- Incident severity gauged by injury severity

\subsection{Objective}

Our objective was to learn whether or not there was a difference in frequency and injury severity at SS-Rail as opposed to Non-SS-Rail. Our research question was: Do SS-Rail incidents differ from Non-SS-Rail incidents in driver characteristics, crossing characteristics (active/passive, signage), driving behavior, injury frequency and injury severity? Our dependent variables were the count of incidents and the injury severity (none, injury but no fatality, fatality). Our independent variables were driver characteristics, driving behaviors, and crossing characteristics. 
Our research questions were:

R1. How does the HRGC type relate to driver behavior?

R2. How does the HRGC type relate to the type of outcome (train striking the vehicle or vehicle striking the train, driver's actions and position)?

R3. Does HRGC type relate to the outcome severity (injury severity) of an incident?

R4. Does the incident frequency distribution for HRGC type differ depending on the age or gender of the motor vehicle driver, motor vehicle size, or protection type?

In order to answer the research questions, we extracted data from the FRA database and compared frequency distributions within SS-Rail and Non-SS-Rail. The extracted fields included: driver characteristics such as age and gender, driving behaviors such as speed and stopping, and injury severity as related to variables such as active/passive crossing, storage space, etc.

\subsection{Method}

\subsubsection{Incident Data}

For this study, we used FRA Incident Data from 2017 through 2019, on public HRGCs only, for the states of Florida, Indiana, North Carolina, New York, Pennsylvania, and Washington. Those six states were selected as a follow-up to a previous study that used the SHRP2 NDS database for possible future analyses. The data extraction process included the following:

1. FRA incident data on public HRGCs, from 2017-2019, was pulled, capturing information from the Accident/Incident Report by Railroad, Railroad Injury and Illness Summary, and U.S. DOT Crossing Inventory Forms.

2. Data included information on incident, motor vehicle driver, environment, and railroad crossing.

3. Honed data to six states that were the focus for the study: FL, IN, NC, NY, PA, WA

4. Created a master spreadsheet with information on the following (Table 2.1):

a. Incident report: incident ID, casualties, motor vehicle size/type, driver precrash action, driver position at impact, crossing protection, warnings, injury severity, vehicle speed \& direction, who struck whom, driver demographics, obstruction, and narrative

b. Inventory report: protection, warnings, preemption, highway traffic signal nearby, GPS coordinates (Appendix A1). 
5. Using Google Earth, for each of the records, we captured an image of the crossing from as close to the time of the incident (but not after).

a. Google Earth: short-storage identification, storage space length, protection, warnings, obstruction

6. The reports do not have a field labeled "Short-Storage", so this information was derived from other fields on the reports (e.g., Nearby Highway Intersection, Preemption) and also by the Google Earth images.

7. Error-checked data and cross-referencing information on forms. 


\section{Table 2.1}

Variables defined in FRA database analysis

Variable

Description

\section{Dependent Variable}

Frequency of incidents

Injury Severity

No injury vs Injury/Fatality (collapsed)

Train strike vehicle/Vehicle strike train

Who struck whom in the collision

\section{Primary Independent Variables}

HRGC type SS-Rail/Non-SS-Rail

SS-Rail within 200 feet of highway intersection or preempted

Driver pre-crash behavior

Driver action just before impact (go through/around gates, stop on tracks, etc.)

Driver position at impact

e.g., stopped on track, moving over track

\section{Secondary Independent Variables}

SS-Rail storage space length

Motor vehicle type/size

Passive/Active protection

Presence of Obstruction
Distance between tracks and intersection

Small (automobile, pickup truck ) vs large (bus, semi-truck)

Static (e.g., crossbuck, stop sign, pavement markings) vs timely, dynamic warnings (gate, flashing lights, audible bells)

Presence vs absence of visual obstruction 


\subsubsection{Data Reduction}

An overview of the FRA data pulled and data reduction is in Figure 2.2. Data reduction is described below.

1. All highway-rail incidents from 2017-2019 were a total of 5,653 records.

2. Focusing on six states included in the study, resulted in 1,131 records.

3. Removed 125 records of suicides, pedestrians, bicyclists and non-vehicle incidents where the impact was between something other than a vehicle and train.

4. Records were verified and checked for errors by cross-referencing fields across several reports.

5. Resulting data set included 996 records, of which 226 were SS-Rail.

Figure 2.2

Data Reduction

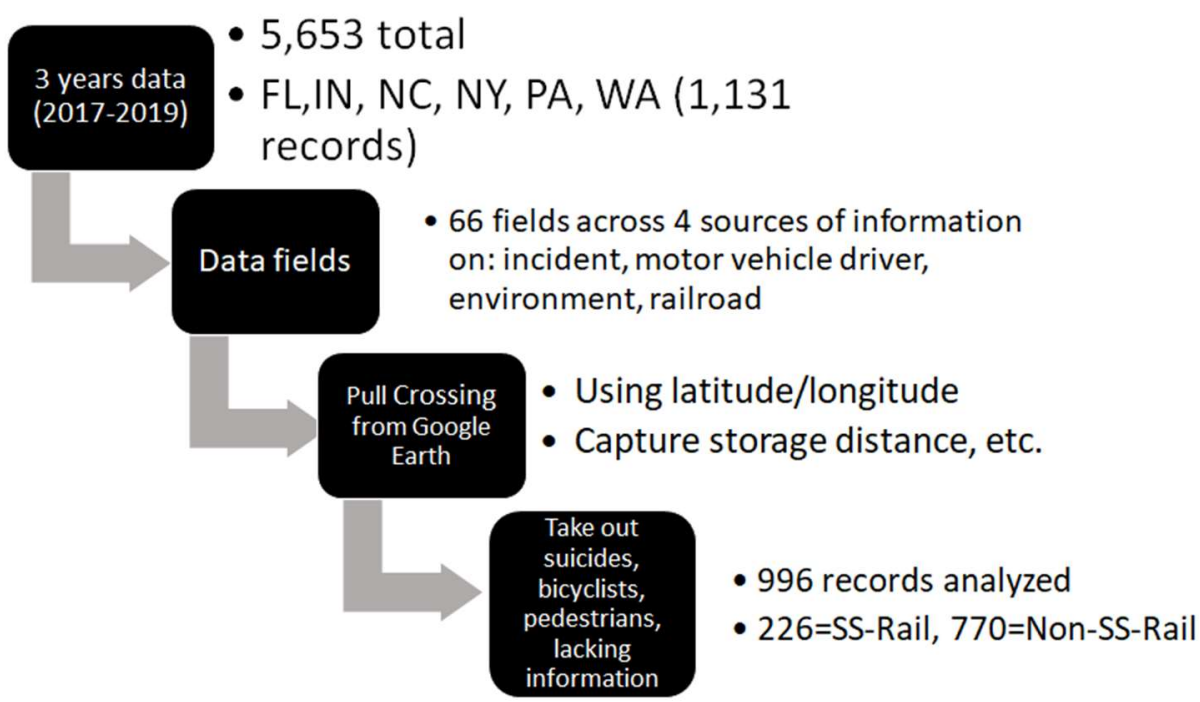




\subsubsection{Coding}

Narratives were analyzed to identify content. Although most narratives restated the information already entered on the forms, there was some new information found in this field, so this field was evaluated separately. Unfortunately, the narrative is filled out by the railroad representative who may or may not have had the opportunity to speak with the vehicle driver, so this information does not completely give information about the driver's cognition just before the incident, as well as at the time of impact. In this study, narratives were used in cases where we needed to check accuracy of other details/components.

\subsection{Results}

First, we describe storage space length of SS-Rail incidents. Then, the results are organized by research question. Outcomes will be presented in terms of HRGC type with driver pre-crash behavior, driver position during impact, injury severity, and whether the train struck the vehicle or vice versa. Please note that in all graphs, the error bars represent the standard error of the mean.

\subsubsection{Storage Space Length}

As mentioned in Chapter 1, the storage space for SS-Rail HRGCs varies quite considerably. Because there is no definitive answer to the question, "How close does an intersection have to be to the HRGC in order for it to be considered an SS-Rail?", the first analysis was to explore the rate of incidents at different SS-Rail HRGC lengths. Recall, our SS-Rail definition for this research is under 200 feet or having a preemption (which may be over 200 feet). In our sample of incidents, the SS-Rail HRGC storage space median length was 58.69 feet, and the mean is 100.44 feet $(S D=102.27)$. As Table 2.6 shows, only $11 \%$ of the incidents fell into the category of preemption and being over 200 feet, while $89 \%$ of the HRGCs were $<=200$ feet. In fact, $50 \%$ of the SS-Rail incidents were at crossings with storage space under 60 feet. Twenty-three percent of all the HRGCs in our sample were SS-Rail.

Although in general, SS-Rail HRGCs occur with storage spaces of 200 feet and under, there are times when a crossing greater than 200 feet has many incidents; this leads to an engineering study. In these cases, sometimes preemption is called for (normal operation of traffic signals is transferred to a special control mode), even for storage spaces over 200 feet. These are also called SS-Rail HRGCs. 
Table 2.6

Storage space length

\begin{tabular}{cc}
\hline Storage Space (feet) & Percentage \\
\hline $0-30$ & $27 \%$ \\
$31-60$ & $10 \%$ \\
$61-90$ & $6 \%$ \\
$91-120$ & $12 \%$ \\
$121-150$ & $8 \%$ \\
$151-180$ & $4 \%$ \\
$181-199$ & $11 \%$ \\
$200+$ & \\
\hline
\end{tabular}

\subsubsection{Driver Behavior}

\section{R1. How does the HRGC type relate to driver behavior?}

This question was assessed by examining the effect of HRGC type on driver action before impact and on the vehicle position at impact.

The FRA data includes information on the driver's action before impact. For this analysis, we considered four categories:

- $\quad$ did not stop (FRA did not stop, went around the gate, went around/thru temporary barricade, or went thru the gate),

- stopped on the crossing,

- stopped and then proceeded,

- other 
In support of R1, a chi-squared test found that driver's action before impact and HRGC type were statistically associated, $\mathrm{X}^{2}(3, \mathrm{n}=996)=34.77, p=.0001$. For SS-Rail HRGCs, drivers were stopped on the crossing just before impact $52 \%$ of the time and did not stop $35 \%$ of the time. Conversely, for Non-SS-Rail HRGCs, drivers were stopped on the

crossing just before impact $31 \%$ of the time and did not stop $53 \%$ of the time (Table 2.2).

Table 2.2

HRGC Type by Driver Action

\begin{tabular}{lccc}
\hline Driver Action & Non-SS-Rail & SS-Rail & Total \\
\hline Did not Stop & $411(53 \%)$ & $79(35 \%)$ & 490 \\
Other & $83(11 \%)$ & $22(10 \%)$ & 105 \\
$\begin{array}{l}\text { Stopped and then } \\
\text { proceeded }\end{array}$ & $36(5 \%)$ & $7(3 \%)$ & 43 \\
$\begin{array}{l}\text { Stopped on } \\
\text { crossing }\end{array}$ & $240(31 \%)$ & $118(52 \%)$ & 358 \\
Total & $770(100 \%)$ & $226(100 \%)$ & 996 \\
\hline
\end{tabular}

Also in support R1, the FRA data identifies the driver's position at the time of impact (Table 2.3). To address this question, position at impact was collapsed into two categories: stopped on the crossing (which included blocked on crossing by gates, stalled or stuck on crossing, stopped on crossing, trapped on crossing by traffic) and moving over the crossing. There was a statistically significant association between driver's position and HRGC type, $\mathrm{X}^{2}(1, \mathrm{n}=995)=29.44, p=.0001$. For SS-Rail HRGCs, the majority were stopped on the crossing (62\%), whereas for Non-SS-Rail, the majority (59\%) were moving over the crossing.

Table 2.3

HRGC Type by Driver Position

\begin{tabular}{llll}
\hline $\begin{array}{l}\text { Position with } \\
\text { categories }\end{array}$ & Non-SS-Rail & SS-Rail & Total \\
\hline $\begin{array}{l}\text { Moving over } \\
\text { crossing }\end{array}$ & $450(59 \%)$ & $\begin{array}{l}86 \\
(38 \%)\end{array}$ & 536 \\
$\begin{array}{l}\text { Stopped on } \\
\text { crossing }\end{array}$ & $319(41 \%)$ & $\begin{array}{l}140 \\
(62 \%)\end{array}$ & 459 \\
Total & $769(100 \%)$ & $\begin{array}{l}226 \\
(100 \%)\end{array}$ & 995 \\
\hline
\end{tabular}




\subsubsection{Incident Outcome}

\section{R2. How does the HRGC type relate to the type of outcome (train striking the vehicle or vehicle striking the train, driver's actions and position)?}

Injury severity can also be affected by who struck whom. The impact at an incident occurs when either a train strikes the vehicle, or the vehicle strikes the train. The FRA database calls this circumstance. When examining the injury severity with HRGC type for who hit whom, in support of $\mathrm{R} 2$, there is a statistically significant effect, $\mathrm{X}^{2}(1, \mathrm{n}=995)$ $=18.948, p=.0001$, indicating there were more incidences with the train striking the vehicle, with no injuries. This makes sense, as many times when a vehicle was stopped on the tracks with an arriving train, the driver vacated the vehicle prior to impact. For injuries, there is a statistically significant effect, $\mathrm{X}^{2}(1, \mathrm{n}=659)=17.176, p=.0001$, with more incidents having the train striking the vehicle rather than the vehicle striking the train. For no injuries, there is a statistically marginal effect, $\mathrm{X}^{2}(1, \mathrm{n}=336)=2.79, p=$ .095. For incidents where there were no injuries, with the train striking the vehicle, $65 \%$ occurred at SS-Rail, and 52\% at Non-SS-Rail HRGCs.

For the incidents occurring at SS-Rail HRGCs, 91\% of incidents involved the train striking the vehicle, whereas for Non-SS-Rail HRGCs, only $78 \%$ of incidents involved the train striking the vehicle (Figure 2.3). This is an important difference between SSRail and Non-SS-Rail because it indicates that more vehicles are somehow getting stopped on the tracks at SS-Rail HRGCs.

In further support of R2, when analyzing injury severity by who hit whom (train strike vehicle or vehicle strike train) for SS-Rail HRGCs only, there was a statistically significant association between the two factors, $\mathrm{X}^{2}(1, \mathrm{n}=226)=5.92, p=.015$. At SSRail HRGCs, $65 \%$ of the incidents occurred when the train struck the vehicle and there were no injuries. However, there was no statistically significant association between injury severity and who hit whom for Non-SS-Rail HRGCs. Although, again, the majority of incidents occurred when the train struck the vehicle and there were no injuries (Tables 2.4 and 2.5). 
Figure 2.3

Impact - Who Struck Whom (percentages)

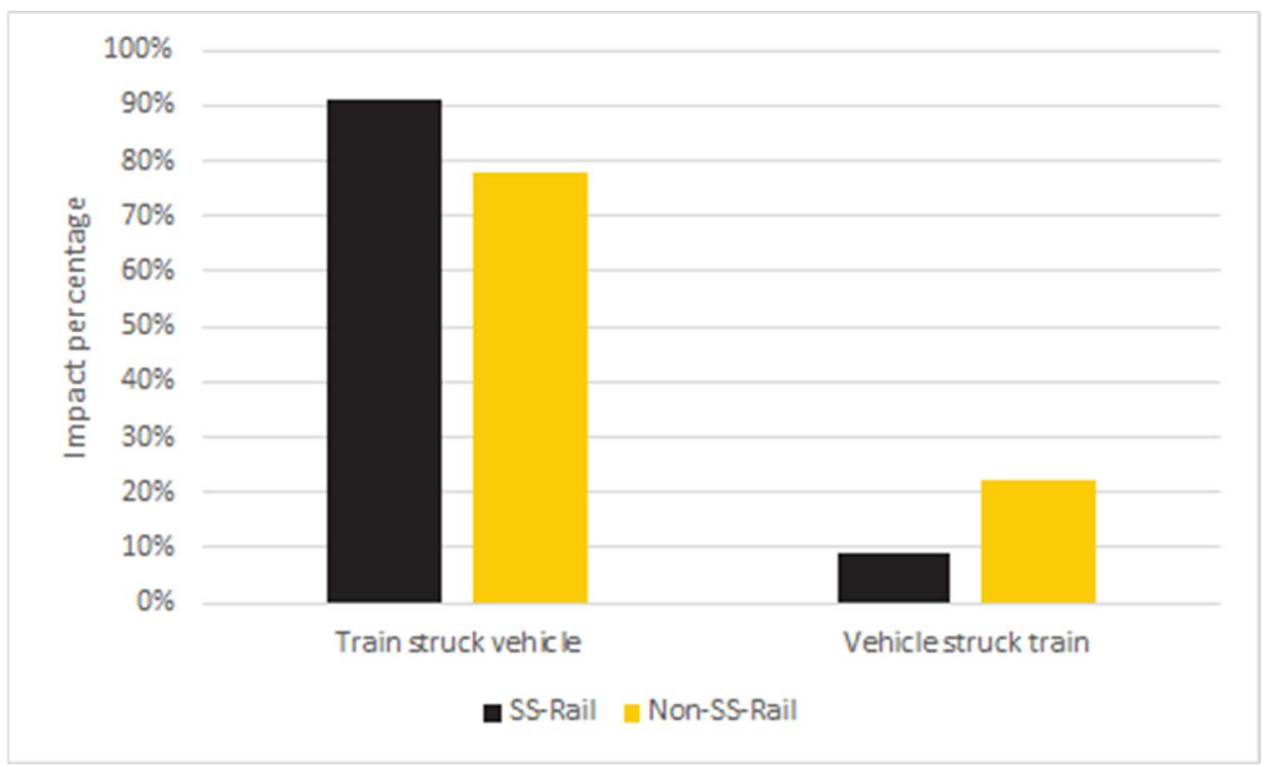

Table 2.4

Injury Severity by Circumstance - SS-Rail

\begin{tabular}{llll}
\hline Injury & $\begin{array}{l}\text { Train struck } \\
\text { vehicle }\end{array}$ & $\begin{array}{l}\text { Vehicle struck } \\
\text { train }\end{array}$ & Total \\
\hline $\begin{array}{l}\text { No } \\
\text { Injury }\end{array}$ & $147(65 \%)$ & $9(4 \%)$ & $\begin{array}{l}156 \\
(69 \%)\end{array}$ \\
$\begin{array}{l}\text { Injury/F } \\
\text { atality }\end{array}$ & $59(26 \%)$ & $11(5 \%)$ & 70 \\
Total & $206(91 \%)$ & $20(9 \%)$ & $(31 \%)$ \\
& & & 226 \\
\end{tabular}


Table 2.5

Injury Severity by Circumstance - Non-SS-Rail

\begin{tabular}{llll}
\hline Injury & $\begin{array}{l}\text { Train struck } \\
\text { vehicle }\end{array}$ & $\begin{array}{l}\text { Vehicle struck } \\
\text { train }\end{array}$ & Total \\
\hline $\begin{array}{l}\text { No } \\
\text { Injury }\end{array}$ & $403(52 \%)$ & $100(13 \%)$ & $\begin{array}{l}503 \\
(65 \%)\end{array}$ \\
$\begin{array}{l}\text { Injury/ } \\
\text { Fatality }\end{array}$ & $199(26 \%)$ & $67(9 \%)$ & $\begin{array}{l}266 \\
(35 \%)\end{array}$ \\
Total & $602(78 \%)$ & $167(22 \%)$ & 769 \\
& & & $(100 \%)$ \\
\hline
\end{tabular}

\subsubsection{Injury Severity}

\section{R3. Does HRGC type relate to the outcome severity (injury severity) of an incident?}

To evaluate research question 3 , we examined injury severity. There was no association between injury severity (no injury, injury, or fatality) with HRGC type, $X^{2}(2, n=996)=$ $1.969, p=.374$, indicating that the frequency of injury severity was the same for both types of HRGCs. Overall, $8 \%$ of incidents had a fatality, $26 \%$ had at least one injury (without any fatalities) and $66 \%$ had no injuries or fatalities.

Because of low frequency of fatalities, we also ran a chi-squared test with two levels of injury severity (no injury vs. injury/fatality). There was also no association between injury severity (no injury, injury or fatality) and HRGC type $\mathrm{X}^{2}(1, \mathrm{n}=996)=.997, p=$ .318 , indicating that the frequency of incidents was the same for SS-Rail and Non-SSRail. (Figure 2.4). 
Figure 2.4

Injury Severity by HRGC Type (percentages)

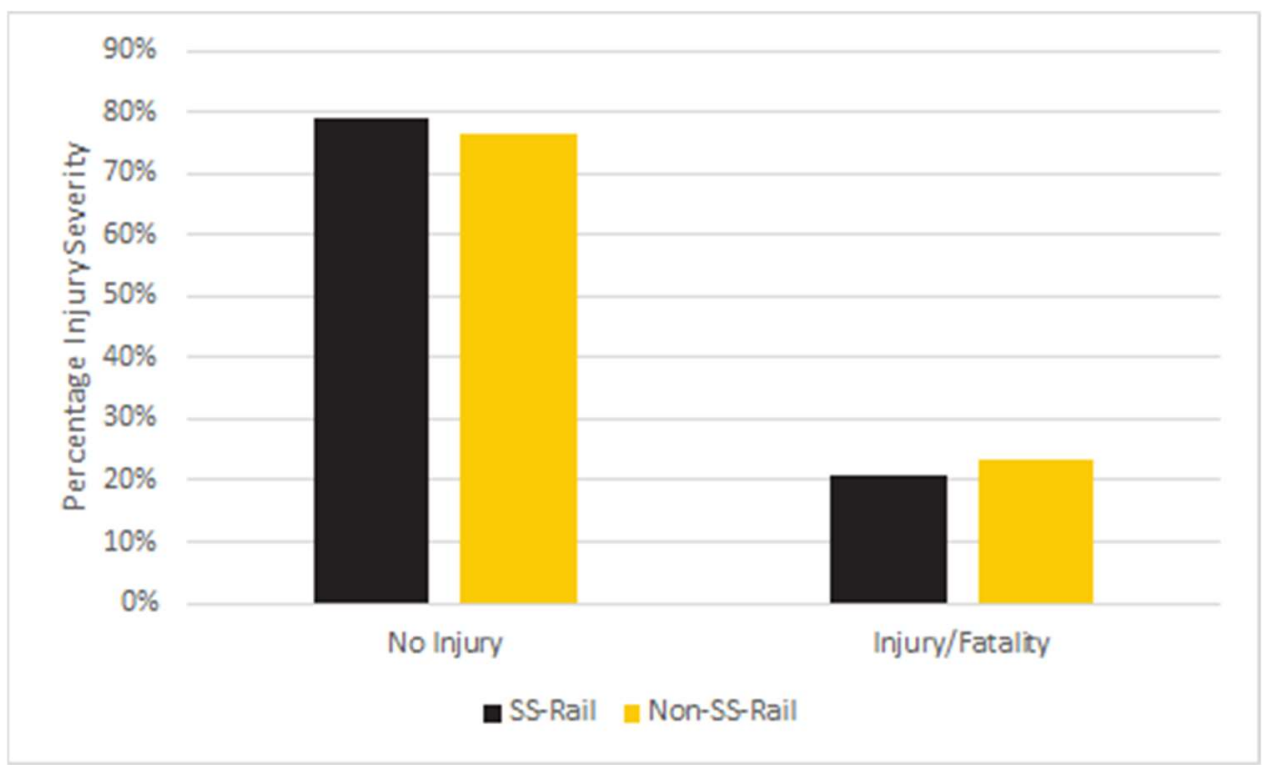

\subsubsection{Demographics, Motor Vehicle Type, Protection Type}

R4. Does the incident frequency distribution for HRGC type differ depending on the age or gender of the motor vehicle driver, motor vehicle size, or protection type?

\subsubsection{Age}

Our last research question involved examining the effect of driver characteristics: age and gender. We performed a chi squared test, in 5 years age groups, with HRGC type, but it was not statistically significant, $\mathrm{X}^{2}(8, \mathrm{n}=804)=13.716, p=.09$, indicating the frequency of incidents was the same for all age groups.

However, there was an interesting pattern when collapsing the drivers into groups of $<=29,30-59$ and $60+$. In partial support of R4, there was a statistically significant effect in Age Groups with HRGC type in this grouping, $\mathrm{X}^{2}(2, \mathrm{n}=804)=7.387, p=.03$.

Whereas the SS-Rail incidents had $24 \%$ occurring with $60+$, Non-SS-Rail had only $18 \%$. This pattern reversed for drivers under 29 years, in which 18\% were SS-Rail and 25\% were Non-SS-Rail. The HRGC percentages for the 30-59 age group were higher and more similar for the HRGC types (Figure 2.5). 
Regarding Injury Severity, drivers who were $<=29$ years of age had $34 \%$ fatalities in SSRail, and only $6 \%$ in Non-SS-Rail. Drivers over 60 years represented $47 \%$ of injuries for Non-SS-Rail, as opposed to 35\% for SS-Rail.

The fact that there was a higher frequency of incidences, but lower level of injury severity might be due to the nature of SS-Rail HRGCs. If drivers were recognizing the additional cognitive burden, they may be slowing down, and this safe pre-crash behavior may result in lower injury severity.

\section{Figure 2.5}

HRGC Type by Age Groups

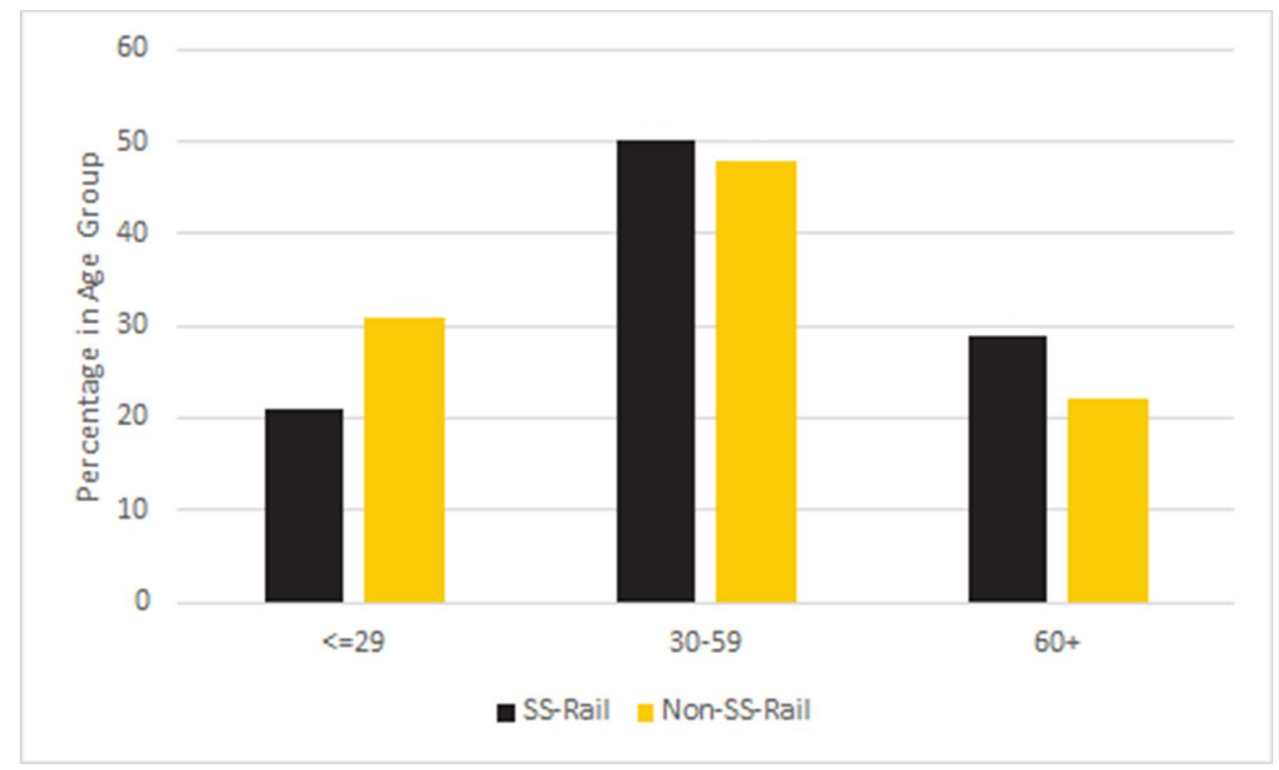

\subsubsection{Gender}

Although males represented $49 \%$ of the United States population in 2017-2019, they represented $65 \%$ of the drivers in incidents. The chi-squared test indicated that HRGC type (SS-Rail, Non-SS-Rail) was not statistically associated with driver gender, $\mathrm{X}^{2}(3$, $\mathrm{n}=924)=3.52, p=.318$ (Figure 2.6$)$. This overall pattern was the same (65\% male) in both HRGCs. 
Figure 2.6

HRGC Type by Gender (percentages)

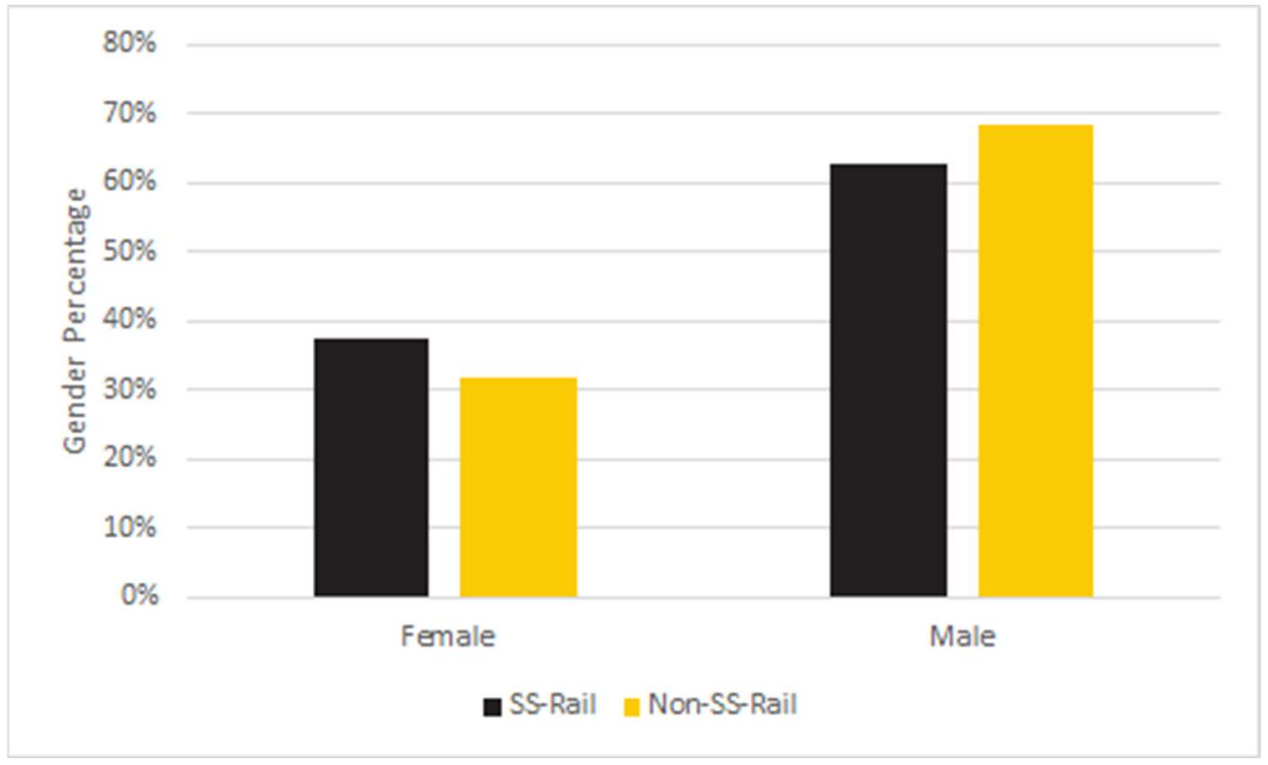

\subsubsection{Motor Vehicle Type}

There was no significant effect of vehicle type/size and HRGC type because there were not enough examples of all types. The motor vehicle types were then collapsed into three categories: small (motorcycle, car, pickup, or van), large (bus, tractor \& trailer, or truck), and other. There was no statistically significant effect of vehicle type with HRGC type, $\mathrm{X}^{2}(2, \mathrm{n}=995)=2.87, p=.238$, indicating there is no difference for motor vehicle type with HRGC type (Table 2.7 ).

\section{Table 2.7}

Percent vehicles

\begin{tabular}{lcccc} 
& $\begin{array}{c}\text { Small } \\
\text { Vehicle }\end{array}$ & $\begin{array}{c}\text { Large } \\
\text { Vehicle }\end{array}$ & Other & Total \\
\hline SS-Rail & $\begin{array}{c}157 \\
(69 \%)\end{array}$ & $17(8 \%)$ & $52(23 \%)$ & $226(100 \%)$ \\
Non-SS-Rail & 573 & & & $770(99 \%)$ \\
& $(74 \%)$ & $40(5 \%)$ & $157(20 \%)$ & \\
\hline
\end{tabular}




\subsubsection{Protection Type}

When examining active or passive protection across crossings, $77 \%$ had active warning devices. To learn whether or not there is a difference for protection type with HRGC type, we performed a chi-square. In partial support of R4, there was a statistically significant relationship between the type of protection and HRGC type, $\mathrm{X}^{2}(1, \mathrm{n}=986)=$ $13.272, p=.0001$. HRGCs with active warning devices represented $86 \%$ of SS-Rail HRGCs compared to $75 \%$ of Non-SS-Rail HRGCs. This result makes sense given SSRail HRGCs have intersections nearby (Figure 2.7).

There is no significant effect for Injury Severity for active or passive protection for neither SS-Rail nor Non-SS-Rail HRGCs.

Figure 2.7

Protection Type by HRGC Type

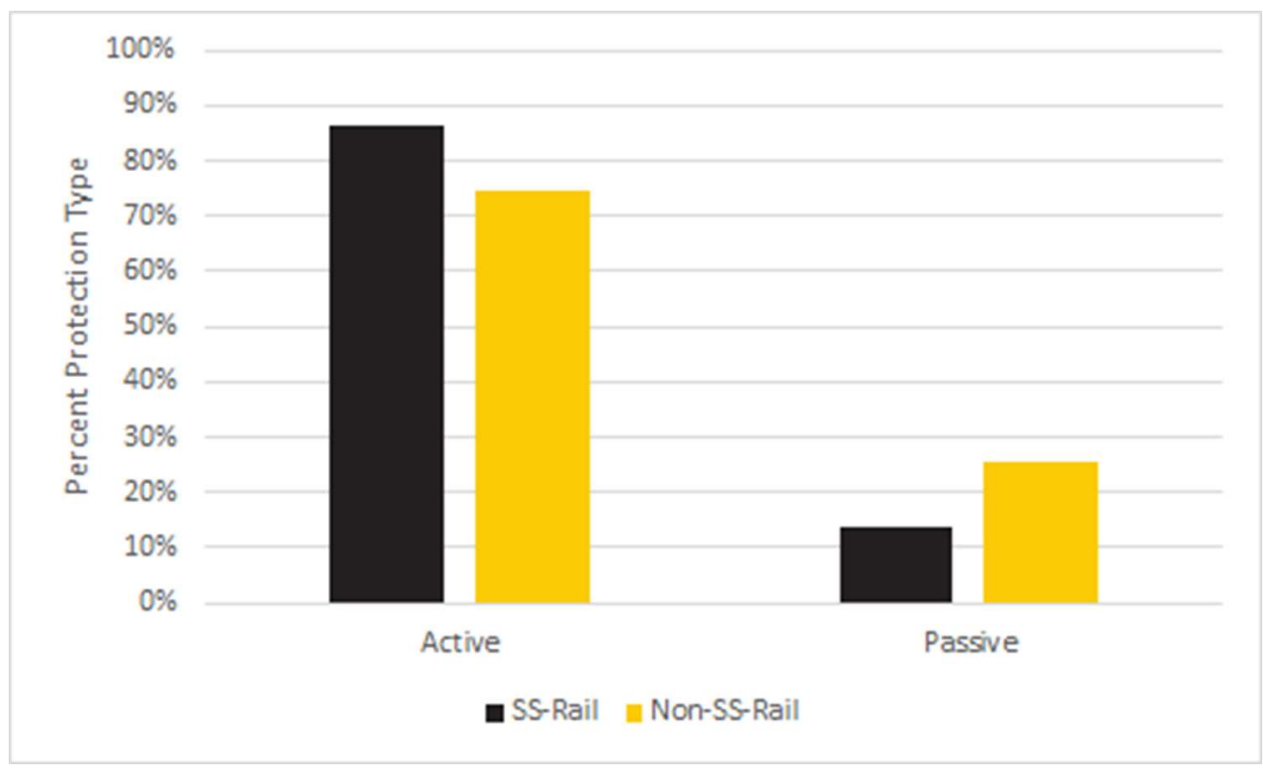

\subsection{Discussion}

R1. How does the HRGC type relate to driver behavior?

In support of R1, results show that HRGC type does affect driver behavior. For SS-Rail, drivers were more likely to be stopped on the track than for Non-SS-Rail. For Non-SSRail, more than half of the drivers did not stop; this is different from SS-Rail, who did not stop one third of the time. This could be due to traffic stopping at the intersection, and drivers having nowhere to go. One benefit of SS-Rail is that drivers are slowing down due to the intersection, and they are not trying to beat the train as much as with Non-SS-Rail. 
Other research has examined the effect of pre-crash behavior on injury severity, finding a statistically significant effect, with more than half of the drivers stopped on the crossing (Liu et al., 2015). We extended this work by demonstrating that this relationship is different for SS-Rail and Non-SS-Rail HRGCs. Complementing the driver's action, is the driver's position at impact. When examining this, we found that the majority of SSRail incidents had drivers stopped on the crossing. However, for Non-SS-Rail incidents, the majority of drivers were moving over the crossing.

R2. How does the HRGC type relate to the type of outcome (train striking the vehicle or vehicle striking the train, driver's actions and position)?

At SS-Rail incidents, $91 \%$ of the incidents resulted in the train striking the vehicle. This is not surprising, since the majority of SS-Rail incidents ended with the vehicles stopped on the track. For Non-SS-Rail, 78\% of the incidents ended with the train striking the vehicle. The majority of the vehicles in Non-SS-Rail incidents were moving over the crossing. Previous literature provided information on injury severity. For example, Liu et al. (2015) found that having active protection decreased the injuries. However, this study examined pre-crash behavior and extended the results into the SS-Rail domain.

R3. Does HRGC type relate to the outcome severity (injury severity) of an incident?

The HRGC type does affect the injury severity of an incident. There was a statistically significant effect of who struck whom with HRGC type. For SS-Rail incidents, $65 \%$ of the incidents happened with the train striking the vehicle where there were no injuries.

R4. Does the incident frequency distribution for HRGC type differ depending on the age or gender of the motor vehicle driver, motor vehicle size, or protection type?

No significant differences found in age, gender, vehicle size/type or storage space. However, with regards to age, there are clear differences for drivers under the age of 30 and above the age of 60 . Although SS-Rail HRGCs only account for $23 \%$ of all HRGCs in this study, 24\% of the incidents at SS-Rail HRGCs involved drivers over the age of 60 . This might be an issue of familiarity, where older drivers do not look at signs as much (Babic et al., 2017), leading them to miss the dynamic nuances of these crossings. Or, perhaps this type of crossing results in a higher cognitive load, which has been shown to slow down response time for older drivers (Lundqvist and Eriksson, 2019). This might explain why drivers under 30 only accounted for $18 \%$ of the incidents at SS-Rail HRGCs. 


\subsubsection{Implications}

This study demonstrates that there are clear differences between SS-Rail and Non-SSRail HRGCs that may inform future safety studies. For example, driver's were more likely to be stopped on the tracks and get struck by a train in SS-Rail HRGCs. There have been many studies on drivers, and even driver behavior at HRGCs; thus far, however, none have focused on the differences between SS-Rail and Non-SS-Rail HRGCs. With this conclusion that the two HRGCs differ, it is clear that interventions might also differ. While interventions that are applied to Non-SS-Rail HRGCs may alleviate the severity and frequency of incidents, these interventions may not improve safety at SS-Rail HRGCs.

The impact is caused either by the train striking the vehicle, or vice versa. At SS-Rail HRGCs, there were more trains striking a vehicle. This makes sense, as there were more instances of the vehicle stopped on the tracks for SS-Rail HRGCs. An intervention here might address the question of why vehicles are stopped on the tracks. Some of these might be caused by a stalled vehicle, but more likely is that the intersection is causing vehicles to get backed up and drivers are not making sure there's room on the other side of the tracks before proceeding over them.

\subsubsection{Limitations and Further Research}

There are a few limitations with this research related to the reporting and archival nature of the data. The FRA database provided useful information on real-world incidents. However, it lacked the detail necessary to analyze driver's decision-making and attention. Although information is provided on pre-crash behaviors there are no fields in the FRA forms to identify the cognitive processes of the driver. We could not capture that information in the FRA narrative fields either. FRA forms are generally filled out after the fact, with most of the narratives repeating information that was previously identified with checkboxes. For example, we are unable to determine if the driver was distracted, running late, a risk-seeker, etc., all of which may lead a driver to try to cross the tracks in front of an arriving train.

Further research might be done with these incidents by looking at the NDS data at these HRGCs. For instance, an incident from the FRA database might be cross-matched with the NDS video of that incident. We would then be able to see what the driver was doing leading up to the incident. 
The FRA data analysis provided insight into Decision Point 2 (the area just before the tracks) and Decision Point 3 (the railroad tracks). We were able to identify the driver's behavior just before the tracks, and their position relative to the tracks as a train passed through. However, we were unable to capture the driver's actions for Decision Point 1 (first warning of an HRGC), nor were we able to learn what the driver was attending to, thinking of, and the decisions they were making. The next study, a lab experiment, seeks to identify driver attention at Decision Point 1, the first indication of an upcoming railroad, and, in the case of a SS-Rail HRGC, an upcoming intersection. Perhaps, learning about driver attention and safety concerns at Decision Point 1 will begin to help us understand what drivers were thinking at Decision Point 2 in the FRA study.

\section{Study 2: Driver Safety Concerns Experiment}

\subsection{Introduction}

Whereas the FRA database gave insight into driver behavior, the next study will give insight into driver cognition. In this experiment, we explore drivers' safety concerns in two types of HRGCs: SS-Rail and Non-SS-Rail. The objective of this experiment was to identify whether or not drivers identified different safety concerns when presented with an SS-Rail or Non-SS-Rail HRGC. Research that focuses on what drivers are paying attention to at different types of HRGCs will improve our understanding of driver behavior and potential interventions for the rarely researched SS-Rail HRGCs (Ambros et al., 2019).

Human factors researchers found that knowing what to do at HRGCs does not mean acting in a manner consistent with that knowledge. For example, Tidwell and Humphreys (1981) found that although most drivers knew what to do at rail crossings, $94 \%$ of the drivers did not properly or safely respond to the HRGC.

In an effort to bridge the study of human error to the driving realm, Salman et al. (2010) found that drivers misjudge the distance between their vehicle and another vehicle or object. In a related study where drivers had to judge moving vehicles and distance, Lenné et al., (2014) found that upgrading a road with signage did not affect drivers' decisions at medium/long gaps.

Furthermore, drivers sometimes do not make good estimates of their ability to handle various situations. This miscalibration is another contributing human factor to unsafe driving (Horrey et al., 2015). For example, if an environment, such as that of an SS-Rail, exceeds that which the driver is able to absorb and possibly react to at their current speed, a driver might calibrate and slow down to enable themselves to consider the intersection, the railroad track, a potentially arriving train, etc. Poorly calibrated drivers might not slow down, ending up in a crucial situation, especially if they are considering only one part of the SS-Rail, such as the intersection only. 
Poor danger detection also plays a role in the incidents. Pelz and Krupat (1974) had participants watch films from the driver's perspective and throughout, identify whether they felt "safe" or "unsafe". The results showed that the safe drivers (those without accidents, violations, or citations within the past year) reacted to hazards sooner, and more gradually than those with violations.

The current study will examine driver's safety concerns in driving scene images. Although hazard perception has been studied from drivers' perspectives, (Huestegge et al., 2010), it has not been directly tied to SS-Rail HRGCs, (Linja et al., 2020).

This experiment also uses eye-tracking to explore drivers' eye movements when evaluating a driving scene for safety concerns. Using eye-tracking and annotation together provided finer detail on drivers' visual behavior. Recarte and Nunes (2000) found that fixations were longer during spatial-imagery tasks. It may be possible to have different gaze durations in different types of imagery; for example, an SS-Rail HRGC vs a Non-SS-Rail HRGC. Di Nocera et al. (2006) used a Nearest Neighbor Index algorithm with eye-tracking to identify differences in pilots' fixations dependent on mental workload. When workload was high, the scanpath spent shorter times at necessary equipment. Fixations have been found to increase when presented with safety concerns identified by drivers (Chapman and Underwood, 1998; Kim et al., 2019) and different fixation patterns can be found when comparing novice and expert drivers (Underwood et al., 2003). Therefore, the fixations of younger drivers were analyzed as a part of the present experiment.

\subsection{Objective}

The present study seeks to answer the following research questions:

R1: Do drivers report different numbers of safety concerns depending on HRGC type, obstruction, or driving experience?

R2: Do drivers report a higher level of average severity of those concerns in SS-Rail HRGCs than Non-SS-Rail HRGCs? Does that pattern depend on obstruction or driving experience?

R3: Does the number of safety concerns or impact of those concerns differ by driver safety knowledge?

R4: Does the content of safety concerns differ depending on HRGC type?

In order to answer these questions, we conducted an experiment where participants were asked to identify safety concerns in driving scenes. 


\subsection{Method}

\subsubsection{Participants}

Forty-eight college-aged drivers ( $59 \%$ male), average age of 19 years $(S D=0.84)$, with 3.88 years $(S D=1.1)$ of driving experience completed the 60 -minute study in exchange for Introduction to Psychology course credit. Participants were recruited based on where they did most of their driving (rural or urban/suburban roads), which resulted in 18 rural and 30 urban drivers in the study.

\subsubsection{Safety Concern Task}

For this task, we used Psychology Experiment Building Language (PEBL, Mueller and Piper, 2014) (Figure 3.1), based in part on a threat-detection task (Zimmerman et al., 2011). First we identified SS-Rail and Non-SS-Rail HRGCs from the 2011-2013 2nd Strategic Highway Research Program (SHRP2) Naturalistic Driving Study (Hankey, et al., 2016; Lautala et al. 2018; Muhire et al., 2017; Salim et al., 2018). We captured a range of crossings, then identified four SS-Rail and four Non-SS-Rail images, half with visual obstruction preventing clear view of the potentially approaching train and half with no such obstruction. The entire set included these target images and three filler images (driving scenes without railroad crossings). All images were publicly available and pulled from Google Earth.

Figure 3.1

PEBL Safety Concern Task Screen

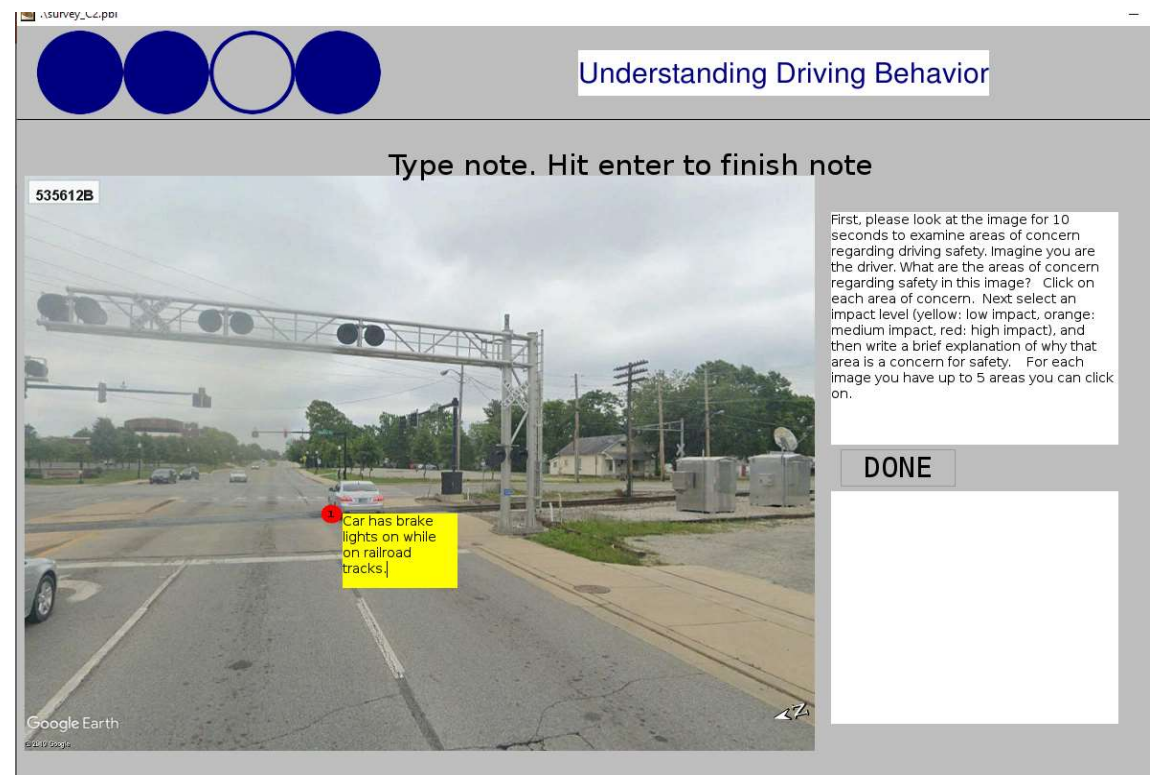




\subsubsection{Procedure:}

The participants completed the study individually via a computer in the lab. Participants were randomly assigned to one of three randomized driving scene orders. To minimize the likelihood of response biases, participants were not told that the study related to railroad crossings, but rather, that it was a study about safety concerns in driving scenes. They were given the following instructions: "You will be shown images in this study. Look at the image for 10 seconds to make sure you see the entire scene. Then, imagine you are the driver in the vehicle from the perspective of the image. What areas of this scene would you be concerned with safety-wise?" Participants were instructed to annotate their concerns: "Click on each safety concern, then rate how concerned you are (Low, Medium, High), and briefly explain your concern."

Following the instructions, participants performed several practice rounds and proceeded only when it was clear that they understood the task to be performed.

The participants then completed safety concern severity ratings and annotations for all eleven images, with up to five safety concerns for each, for a total of 55 safety concerns.

After completing the annotations, participants completed a short questionnaire about their driving experience (rural vs. urban), demographic information, and a seven-item safety knowledge test (adapted from Landry, 2016) that was updated to include SS-Rail HRGC signage (scores ranged from 3-7). Included in the questionnaire were questions about how often they encountered railroad crossings, how dangerous they found them, and a knowledge test of railroad advance warning signage. This information (Appendix A2) allowed us to examine and potentially rule out alternative explanations of the data.

\subsubsection{Coding Scheme}

There were 1,230 safety concerns identified by participants. We analyzed safety concerns across two dimensions - dynamic and static, and whether the concern focused on vehicle, railroad related objects, non-railroad related signage, and/or environment (Table 3.1). Two independent raters coded the concerns for static and dynamic and then into four subcategories: vehicle, railroad related, non-railroad related signage, and environment. After several rounds of training on a subset of the safety concerns (i.e., 30 concerns each round), the raters achieved a high interrater reliability with a Cohen's Kappa $=.93$ across these eight categories. Next, each rater coded half of the remaining safety concern data. Note that 44 safety concerns were not included in the analysis below, either because they were not-codable (no information) or were in the "other" category. 
Table 3.1

Safety Concerns Coding Scheme with Examples

\begin{tabular}{|c|c|c|}
\hline & Dynamic & Static \\
\hline Vehicles & $\begin{array}{l}\text { Vehicles in or entering } \\
\text { the lane }\end{array}$ & $\begin{array}{l}\text { Parked vehicles on the side } \\
\text { of the road }\end{array}$ \\
\hline $\begin{array}{l}\text { Railroad } \\
\text { related }\end{array}$ & $\begin{array}{l}\text { Gate, barrier gate, } \\
\text { signals, train }\end{array}$ & $\begin{array}{l}\text { Rail pavement warnings or } \\
\text { railroad sign }\end{array}$ \\
\hline $\begin{array}{l}\text { Non-railroad } \\
\text { related } \\
\text { signage }\end{array}$ & Traffic light & Stop sign, road sign \\
\hline Environment & $\begin{array}{l}\text { Airplane, construction } \\
\text { work }\end{array}$ & Buildings, trees \\
\hline
\end{tabular}

\subsubsection{Eye-tracking}

We collected eye fixations and gaze durations during the first 10 seconds of the task using a Tobii Pro X3-120 screen-based eye tracker using Tobii Studio software. The X3120 has a $120 \mathrm{~Hz}$ gaze sampling frequency, 0.4 degrees of accuracy, and less than $11 \mathrm{~ms}$ of system latency. We utilized the I-VT fixation filter in Tobii Studio, which identifies eye movements based on the velocity of the directional shifts of the eye.

Prior to starting the task, participants went through Tobii's 9-part calibration procedure within Tobii Studio to confirm that the participants were seated at the proper viewing distance so that we could ensure good eye-tracking data. Stimuli was presented on a 21 inch computer monitor at a viewing distance of about 31 inches. Data on fixations and areas of interest (AOIs) was captured to explore eye movement patterns during the task.

The driving scenes were parsed into five Areas of Interest (AOIs) (Figure 3.2). The AOIs were specific to each driving scene, however, the center AOI always included the tracks and warnings. Then the space above that was split into left and right AOIs, titled $\mathrm{L}$ Downstream and $\mathrm{R}$ Downstream, respectively. The space below the tracks and warning were split in the same way. Those were titled L_Upstream and R_Upstream. 
Figure 3.2

Areas of Interest in eye-tracking software. Used to group fixations

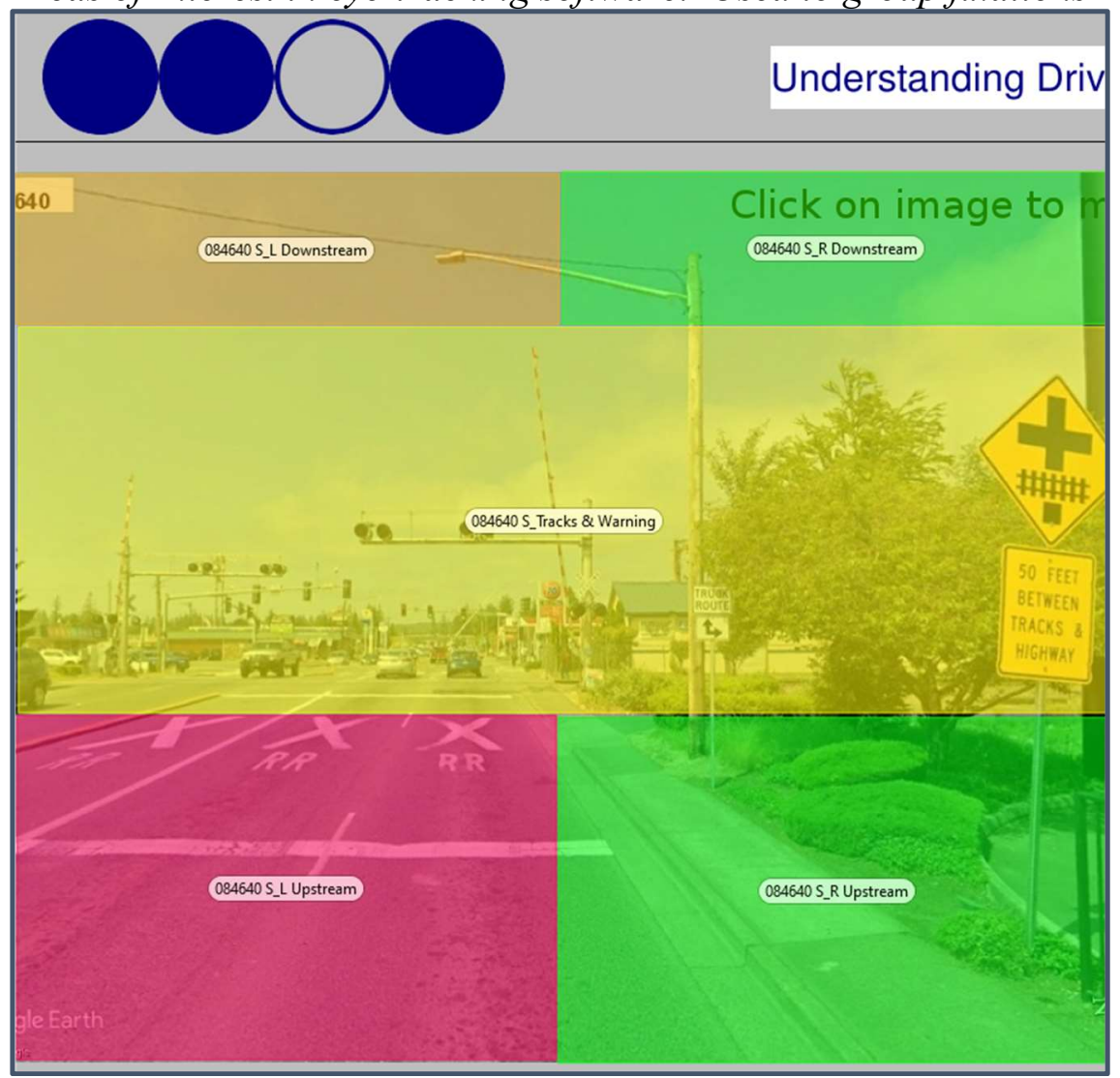

\subsection{Results}

The number and severity of safety concerns were analyzed separately using a mixedfactor analysis of variance design (ANOVA). The 1,230 reported safety concerns were coded and analyzed using a chi-squared test of independence for static and dynamic concerns, separately. Together, these analyses evaluated whether participants' safety concerns depended on the type of rail crossing.

R1: Do drivers report different numbers of safety concerns based on the rail HRGC type? Does it depend on the presence of obstruction or driving experience? 
To answer R1, we analyzed the number of safety concerns using a 2 Rail HRGC type x 2 Obstruction x 2 Driving Experience mixed-factorial ANOVA design. Rail HRGC type (SS-Rail vs. Non-SS-Rail) and Obstruction (present or absent) were the within-subjects variables, while Driving Experience (rural, urban) was a between-subjects variable. The overall 3-way interaction was statistically significant, $F(1,46)=4.38, p=.042$, but none of the $2 \times 2$ ANOVAs were statistically significant. In support of R1, there was a main effect of Rail HRGC type on the average number of safety concerns reported, $F(1,46)=$ 21.23, $p<.001$, effect size $=.34$, with participants reporting more safety concerns for SS-Rail HRGCs $(M=3.17, S D=1.29)$ than Non-SS-Rail HRGCs $(M=2.84, S D=1.29)$, (Figure 3.3). There was a marginally significant main effect of Obstruction on safety concerns, $F(1,46)=3.46, p<.069$. There was no main effect for Driving Experience, $F(1,46)=0.14, p=0.96$, indicating rural and urban drivers reported similar numbers of safety concerns (Figure 3.4). Participants reported more safety concerns in SS-Rail HRGC images than in Non-SS-Rail HRGC images, but the number did not depend on the participant's driving experience (rural or urban), or whether there was obstruction present in the image (Figure 3.4).

\section{Figure 3.3}

Average Number of Safety Concerns by HRGC Type

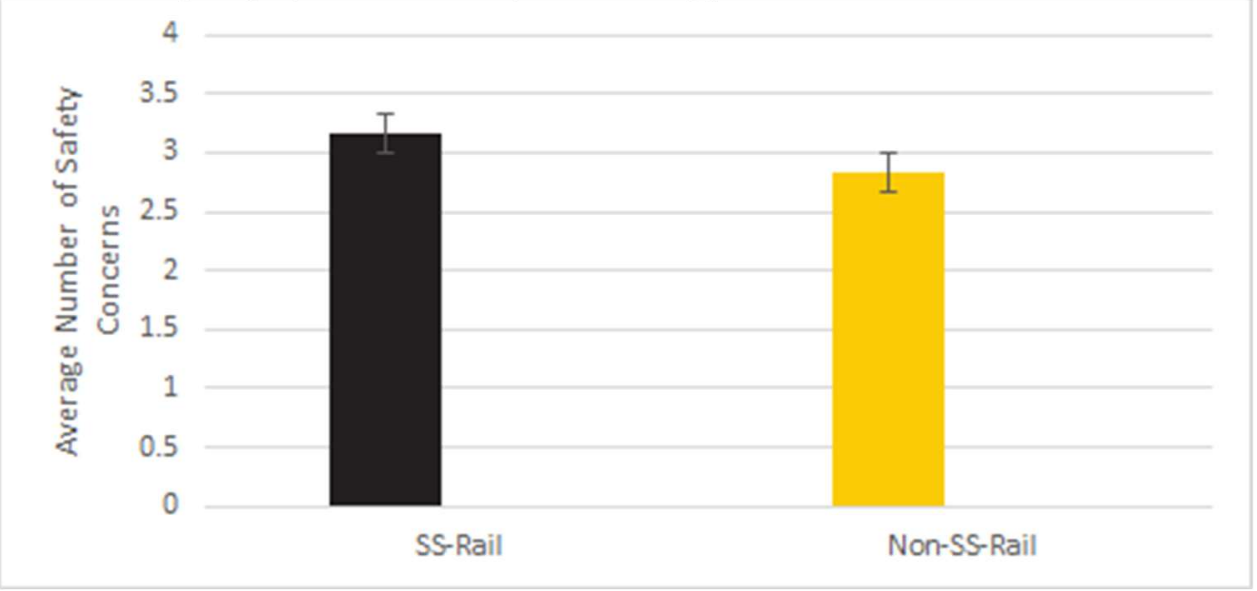


Figure 3.4

Effect of rail HRGC type and presence of obstruction on average number of safety concerns

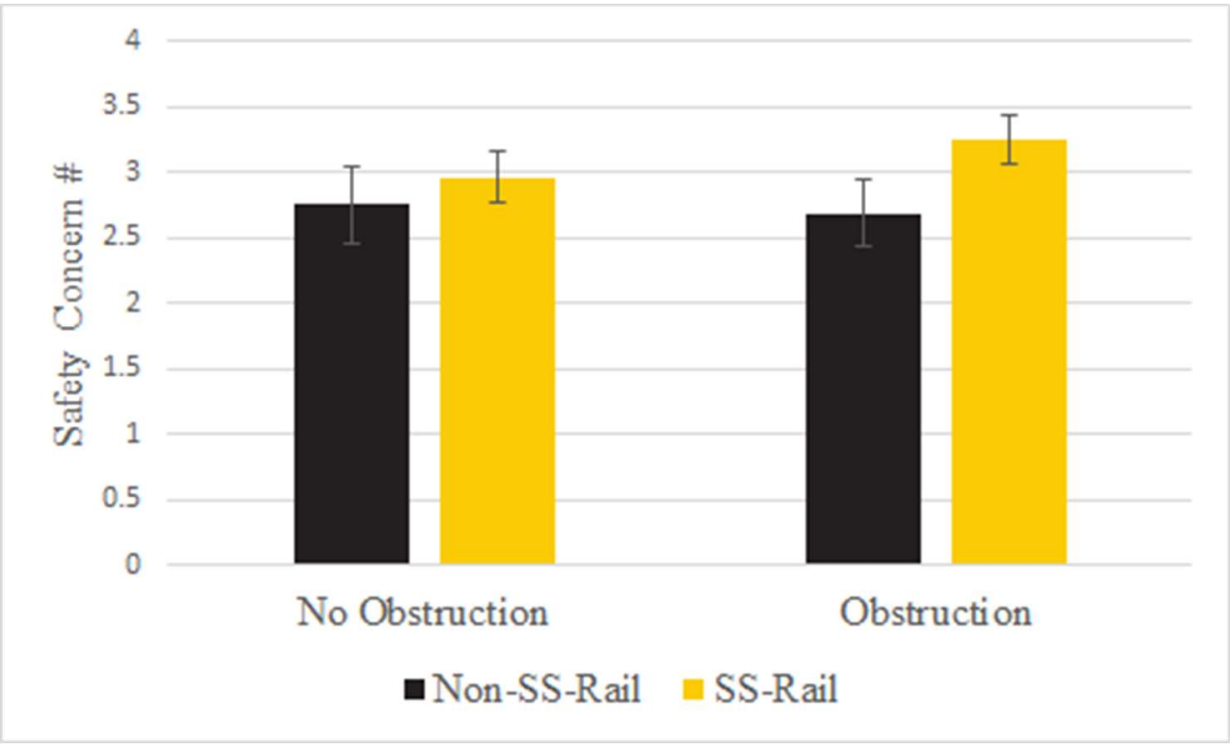

R2: Do drivers report a higher level of average severity of those concerns in SS-Rail HRGCs than Non-SS-Rail HRGCs? Does that pattern depend on obstruction or driving experience?

We analyzed the average severity ratings (scale 1-3) per safety concern using a 2 Rail $H R G C$ type x 2 Obstruction x 2 Driving Experience mixed factorial ANOVA. The 3way interaction was not statistically significant, $F(1,46)=0.15, p=.688$. In support of $\mathrm{R} 2$, there was a main effect of HRGC type on severity rating, $F(1,46)=12.41, p=.013$. Participants gave higher severity ratings on average for SS-Rail HRGC images $(M=$ $1.82, S D=.73)$, than for the Non-SS-Rail HRGC images $(M=1.72, S D=.76)$, (Figure 3.5). Participants' severity ratings did not depend on the presence of Obstruction, $F(1,46)=1.27, p=.265$, or Driving Experience, $F(1,46)=0.96, p=.331$. Not only did participants report more safety concerns for SS-Rail HRGCs than Non-SS-Rail HRGCs, the safety concerns were rated more severe on average (Table 3.2). 
Figure 3.5

Average Severity of Safety Concerns by HRGC Type

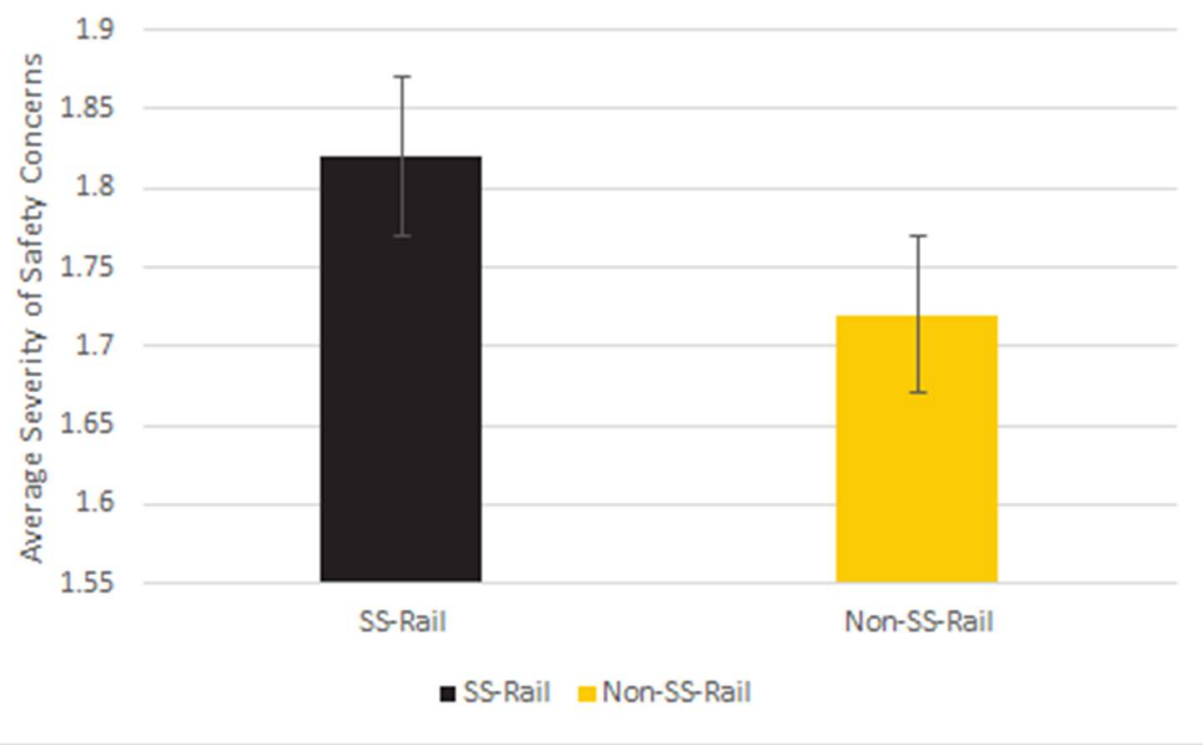

Table 3.2

Average Safety Concern Severity with Obstruction

Average Severity Rating (range = 1 (low severity)-3 (high severity)

\begin{tabular}{lll}
\hline & Obstructed & Not Obstructed \\
\cline { 2 - 3 } SS-Rail & 1.84 & 1.85 \\
Non-SS-Rail & 1.71 & 1.72 \\
\hline
\end{tabular}


R3: Does the number of safety concerns or impact of those concerns differ by driver safety knowledge?

Using a median split of the knowledge scores, a 2 Rail HRGC type $\mathrm{x} 2$ Rail Knowledge (Low, High) mixed-factorial ANOVA indicated a marginally significant main effect of Rail Knowledge on the number of safety concerns reported, $F(1,46)=3.86, p=0.055$, but no effect on the severity ratings, $F(1,46)=2.43, p=0.126$. There was also no statistically significant interaction, $F(1,46)=0.14, p=0.72$. In support of $\mathrm{R} 3$, on average, participants with higher knowledge of the railroad rules identified more safety concerns, regardless of rail HRGC type, than those with lower knowledge of rules. However, this knowledge did not impact their severity scores (Table 3.3). Next, we analyzed the content of the safety concerns.

Table 3.3

Average Safety Concern Severity by Safety Knowledge

Average Severity by Safety Knowledge Median Split

$\begin{array}{ll}\text { Above Average Median Split } & 1.87 \\ \text { Below Average Median Split } & 1.69\end{array}$

\section{R4: Do the types of concerns differ depending on HRGC type?}

Overall, $41 \%$ of the safety concerns described static objects in the image that were not moving or changing (e.g., stop sign, parked vehicle, tree), while 59\% referenced dynamic safety concerns (e.g., traffic light might change, vehicle might switch lanes, train may come) (Table 3.4). Each safety concern received one code. To evaluate R4, we compared the frequency distribution of four types of safety concerns for SS-Rail HRGCs and Non-SS-Rail HRGCs, separately. A chi-squared test of independence indicated no relationship between type of Static Safety Concerns and Rail HRGC type, $\chi^{2}$ (3) $=4.42, p$ $=.11$ (Table 3.5). Participants focused on similar information, regardless of rail HRGC type. Most static safety concerns focused on rail-signage $(\sim 55 \%)$, followed by environment $(\sim 25 \%)$, and non-rail signage $(\sim 15 \%)$. Very few static safety concerns referred to parked vehicles $(0.8 \%)$ in either rail HRGC type. This pattern did not change for SS-Rail HRGCs vs. Non-SS-Rail HRGCs, indicating that drivers were paying attention to similar static information in both crossing contexts. 
Table 3.4

Safety Concern Annotation Samples

\begin{tabular}{|c|c|c|}
\hline Type of crossing & sample comment & dynamic/static \\
\hline SS-Rail & $\begin{array}{l}\text { "There isn't much } \\
\text { space between the } \\
\text { tracks and a busy } \\
\text { road: be wary" }\end{array}$ & static \\
\hline Non-SS-Rail & $\begin{array}{l}\text { "I do not like that } \\
\text { you can't see the } \\
\text { tracks in that } \\
\text { direction until } \\
\text { you're almost on } \\
\text { them." }\end{array}$ & static \\
\hline SS-Rail & $\begin{array}{l}\text { "Train crossing } \\
\text { ahead - stop before } \\
\text { tracks if trains are } \\
\text { coming" }\end{array}$ & dynamic \\
\hline Non-SS-Rail & $\begin{array}{l}\text { "Watching for } \\
\text { signals for an } \\
\text { incoming train. } \\
\text { These can happen at } \\
\text { unexpected times." }\end{array}$ & dynamic \\
\hline
\end{tabular}

Table 3.5

Distribution of Static Safety Concerns by Rail HRGC type

\begin{tabular}{lrrrrr}
\hline HRGC type & $\begin{array}{r}\text { Vehicle } \\
\text { (parked) }\end{array}$ & $\begin{array}{r}\text { Rail } \\
\text { Related }\end{array}$ & $\begin{array}{r}\text { Non-Rail } \\
\text { Signage }\end{array}$ & $\begin{array}{r}\text { Environ- } \\
\text { ment }\end{array}$ & Total \\
\hline Non-SS-Rail & 2 & 140 & 36 & 68 & 246 \\
& $(0.8 \%)$ & $(56.9 \%)$ & $(14.6 \%)$ & $(27(6 \%)$ & $100 \%)$ \\
SS-Rail & 0 & 156 & 52 & 55 & 263 \\
& $(0 \%)$ & $(58.2 \%)$ & $(17.3 \%)$ & $(24(2 \%)$ & $100 \%)$ \\
\hline
\end{tabular}


In contrast, a chi-squared test between Dynamic Safety Concerns and Rail HRGC type indicated a statistically significant association, $\chi 2(3)=87.26, p=.0001$. Participants paid attention to different safety concerns depending on the rail HRGC type (Table 3.6). For Non-SS-Rail HRGC images, participants noted traffic concerns (76\%) more often than rail-related signage and trains $(15.7 \%)$. For SS-Rail HRGC images, the distribution was different. For SS-Rail HRGCs, there was a more even split between traffic $(42.6 \%)$ and rail related cues $(36.8 \%)$, than for Non-SS-Rail HRGCs. Participants noted more safety concerns on rail related dynamic concerns (36.8\%) in SS-Rail HRGCs, as expected. Interestingly, this means participants focused less on traffic in SS-Rail HRGCs, as compared to Non-SS-Rail HRGC images.

Table 3.6

Distribution of Dynamic Safety Concerns by Rail HRGC type

\begin{tabular}{lccccc}
\hline $\begin{array}{l}\text { HRGC } \\
\text { type }\end{array}$ & Traffic & $\begin{array}{l}\text { Rail } \\
\text { Related }\end{array}$ & $\begin{array}{l}\text { Non-Rail } \\
\text { Signage }\end{array}$ & $\begin{array}{l}\text { Environ- } \\
\text { ment }\end{array}$ & Total \\
\hline $\begin{array}{l}\text { Non-SS- } \\
\text { Rail }\end{array}$ & 238 & 49 & 8 & 18 & 313 \\
& $(76.0 \%)$ & $(15.7 \%)$ & $(2.6 \%)$ & $(5.8 \%)$ & $(100 \%)$ \\
SS-Rail & 155 & 134 & 53 & 22 & 364 \\
& $(42.6 \%)$ & $(36.8 \%)$ & $(14.6 \%)$ & $(6.0 \%)$ & $(100 \%)$ \\
\hline
\end{tabular}

\subsubsection{Eye-tracking Results}

Eye-tracking results showed that most fixations were vertically centered around the center area of the driving scenes, horizontally spread across the railroad tracks in HRGC driving scenes (Figures 3.6, 3.7). 
Figure 3.6

Heat Map of One Participant's Fixations for Ten Seconds Prior to Annotation

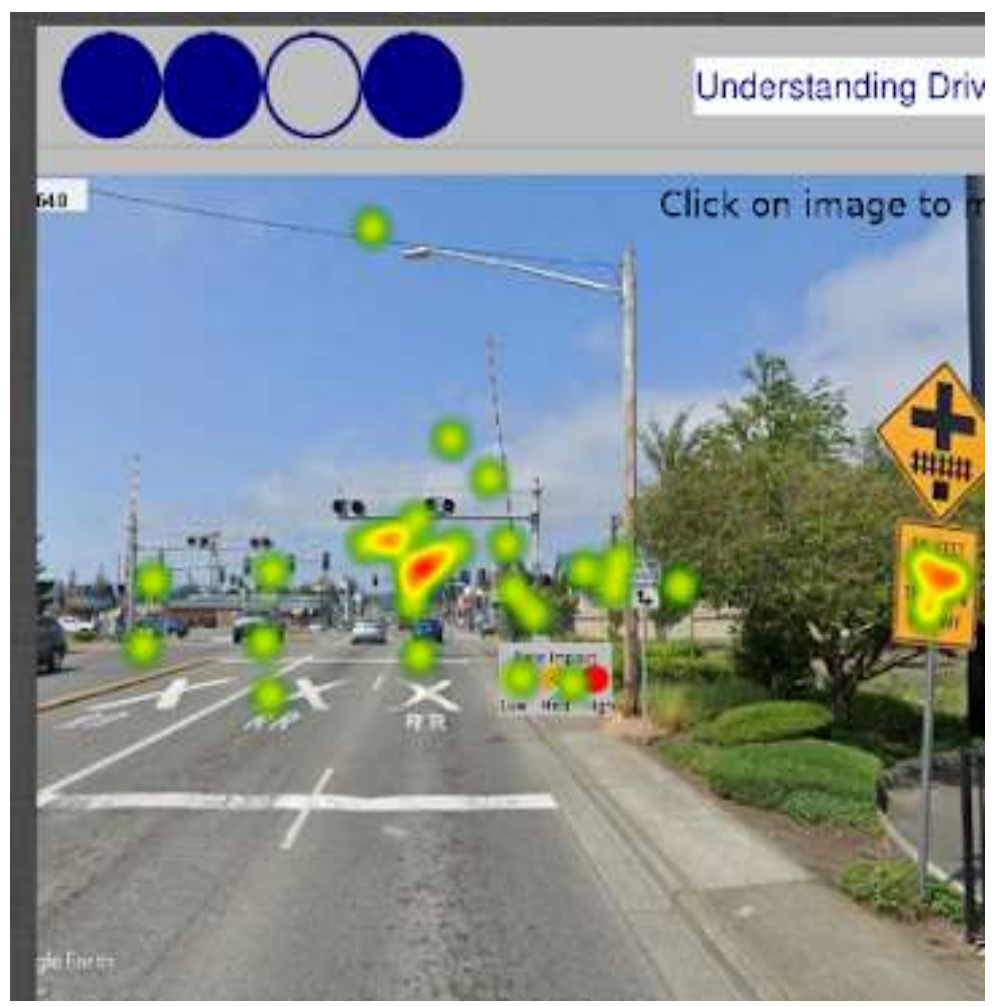


Figure 3.7

Fixations (with durations) From One Participant for Ten Seconds Prior to Annotation

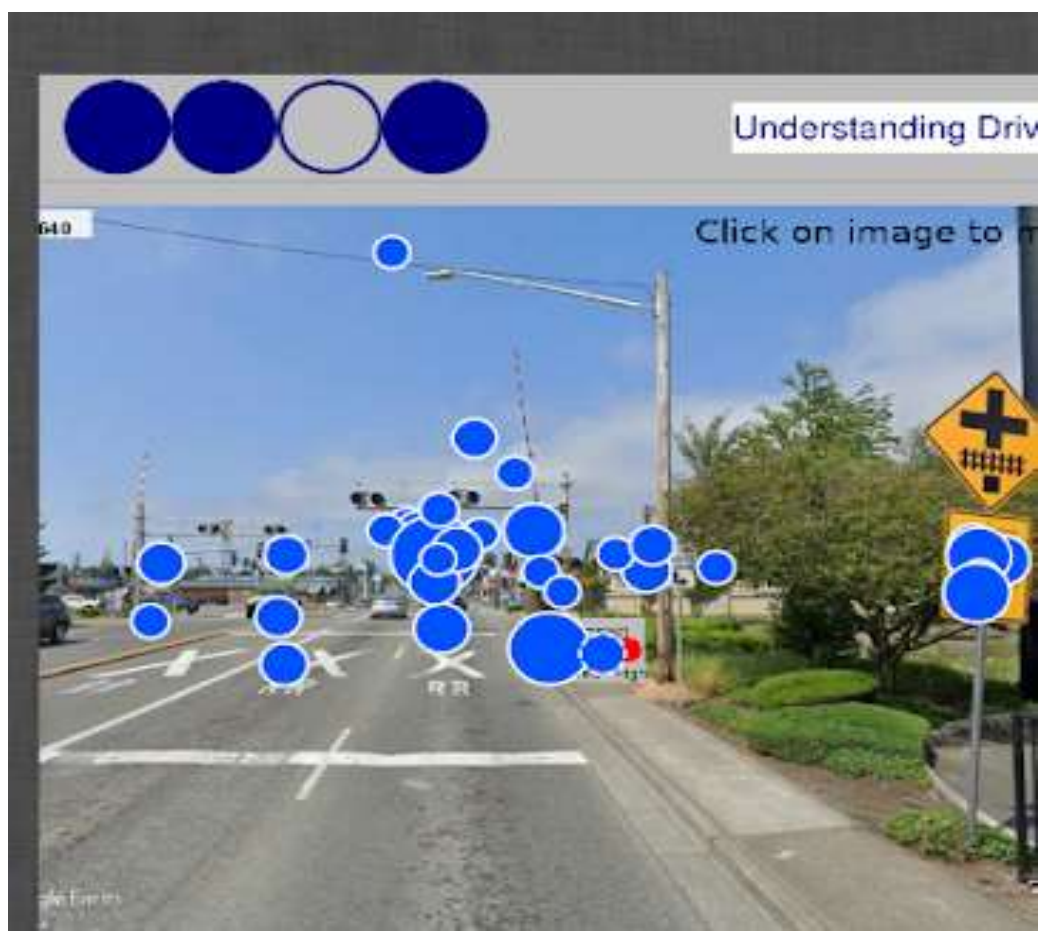

In order to find out if the driver experience (rural/urban) made a difference with HRGC type, we performed a mixed-factorial ANOVA. There was an interaction between Rural/Urban and HRGC Type on gaze duration, $\mathrm{F}(1,7202)=5.82, p=.016$ (Figure 3.8). No main effect of Rural/Urban on gaze duration was found, $\mathrm{F}(1,7202)=0.453, p=.501$. There was a main effect of HRGC on gaze duration, $F(1,7202)=10.27, p=.001$. Drivers with urban experience had longer gaze durations for Non-SS-Rail HRGCs as opposed to SS-Rail. However, this gaze was only about $20 \mathrm{~ms}$ longer. One might posit that gazes were longer at Non-SS-Rail because they are simpler, and there are not many other places to fixate. In an SS-Rail HRGC, there is more to look at, so there are shorter gazes due to a higher number of fixations. However, an opposite stance might be that gazes are longer at Non-SS-Rail objects because the object of attention has a high priority, or is complicated. Nevertheless, the main effect is that Non-SS-Rail HRGC have longer average gaze durations than SS-Rail HRGCs. 


\section{Figure 3.8}

Average Gaze Duration by Driving Experience and HRGC Type

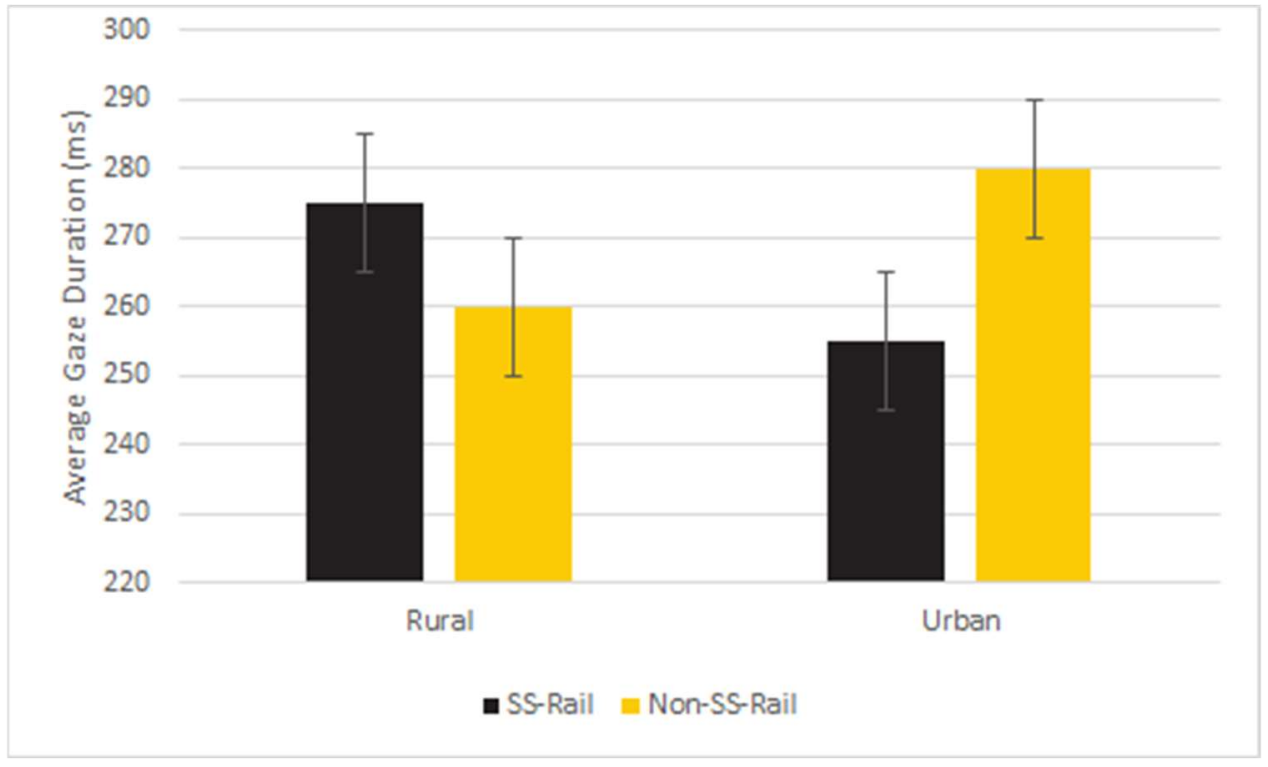

One way to analyze eye-tracking data is to identify the percent dwell time. Another way is to evaluate the fixations. We looked at the number of fixations for SS-Rail vs Non-SSRail. The mean was $\sim 7$ fixations counts for drivers with rural experience, regardless of the type of crossing. However, there was a difference between the two types of HRGCs for drivers with urban experience. The average was almost ten fixations for SS-Rail HRGCS, and only five for Non-SS-Rail HRGCs. That means that urban drivers, who presumably encounter more SS-Rail HRGCs, had almost twice the number of fixations at SS-Rail HRGCs than Non-SS-HRGCs (Figure 3.9). 


\section{Figure 3.9}

Average Fixation Count by Driving Experience and HRGC Type

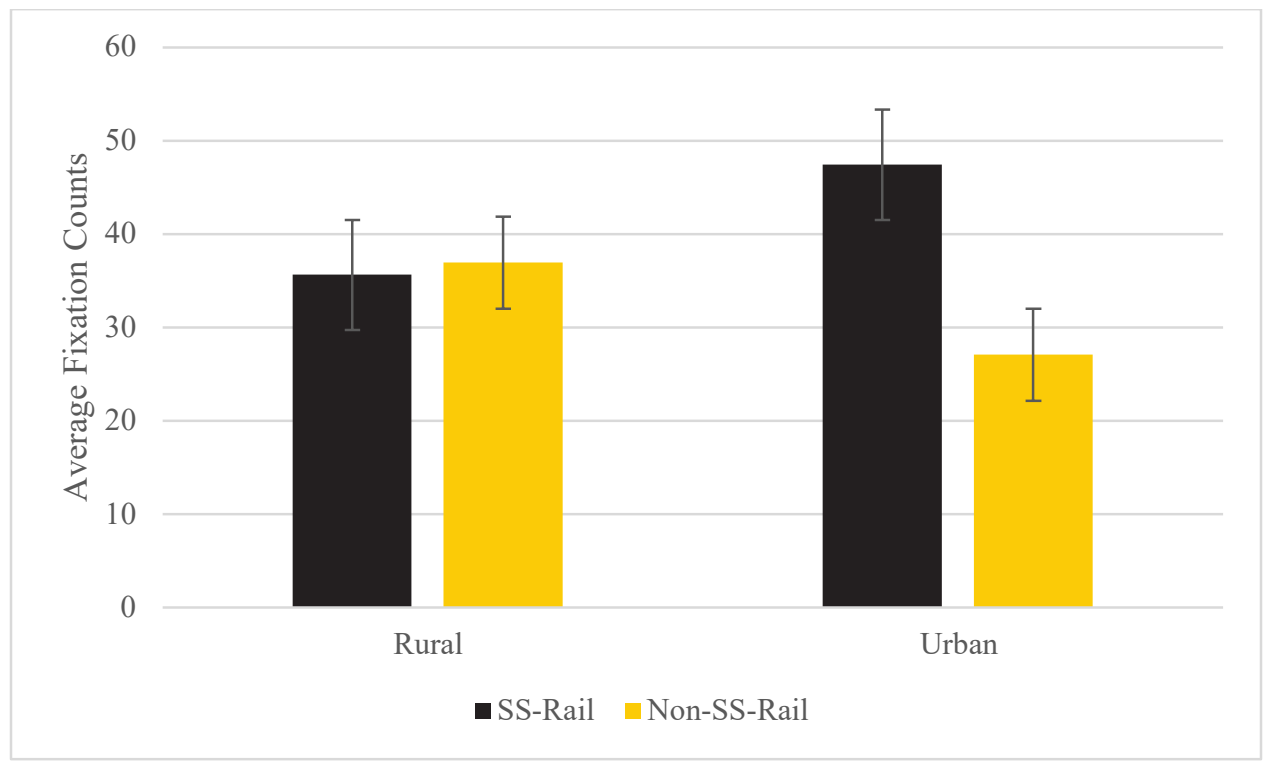

Lastly, the AOIs were split into five spaces: Tracks and Warning, Left \& Right (L \& R) Downstream, and L \& R Upstream. Clearly, most of the fixations were in the Tracks and Warning space. This could be due to the centrality of the tracks in the image. However, when combined with the safety concerns provided by the participants, it was also due to the fact that the railroad objects were in this space. 
Figure 3.10

Average Number of Fixations by Category in AOI spaces by HRGC Type

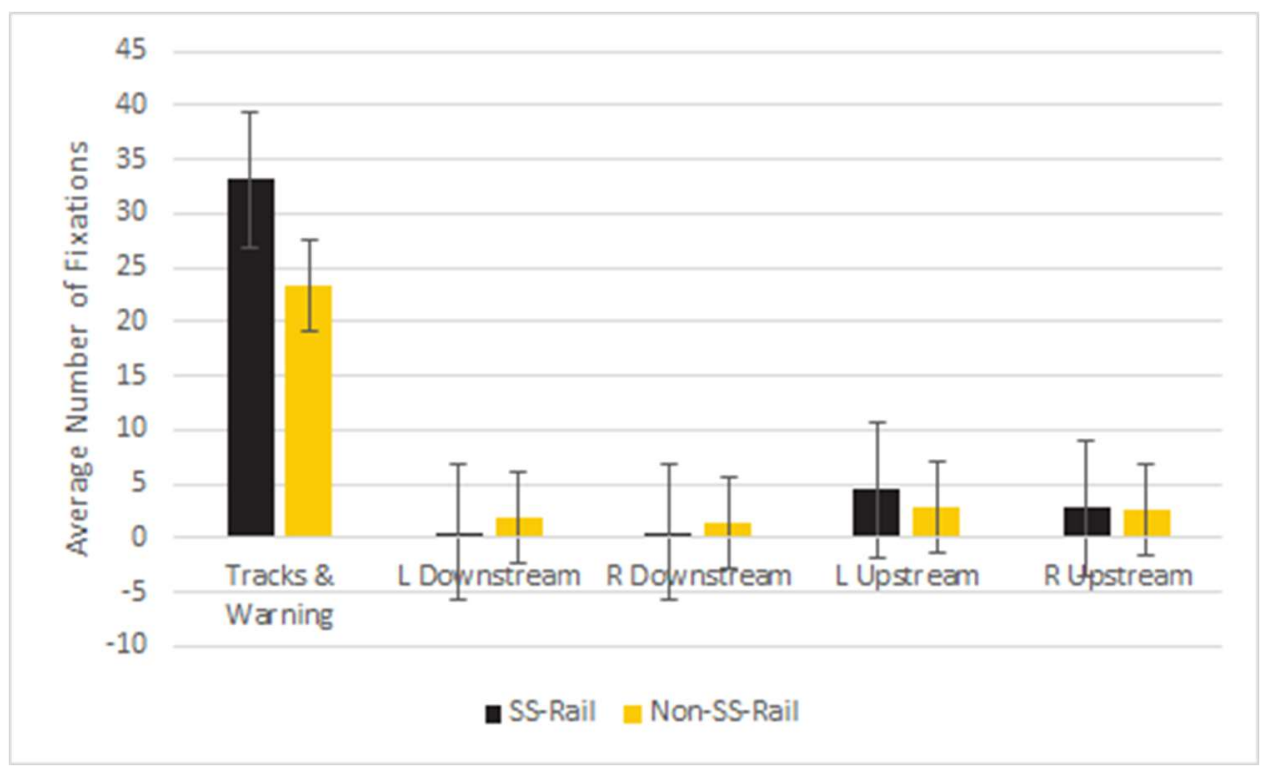

\subsection{Discussion}

Overall, drivers were sensitive to differences in SS-Rail and Non-SS-Rail HRGCs. We found that participants identified more safety concerns at SS-Rail HRGCs than Non-SSRail HRGCs which supported R1. Not only did the number of safety concerns differ, so did the average severity, which supported R2. These ratings depended on the driver's safety knowledge, but not on the presence of obstruction. It is possible that drivers with more knowledge recognize the complexity of the environment and are able to foresee more opportunities for unsafe behavior.

R1 was supported with more safety concerns being reported for SS-Rail than for Non-SSRail HRGCs. This could be because there are more objects to pay attention to at SS-Rail HRGCs. For example, in addition to the railroad track, there is an intersection with a traffic light, so naturally there would be more safety concerns reported. However, the safety concerns that participants identified were not simply additional concerns for additional factors. The safety concerns displayed the participant's awareness of the higher complexity of an SS-Rail HRGC. 
The content of drivers' safety concerns differed by HRGC type. For static concerns (parked cars, signage, etc.), drivers' safety concern annotations did not differ between SSRail and Non-SS-Rail HRGC types. However, they did differ for dynamic information (car changing lanes) with more attention to the rail related information in SS-Rail HRGCs. The difference in what they identified indicated that participants paid more attention to the railroad information than traffic at SS-Rail HRGCs.

These findings are consistent with Tustin et al. (1986), who posited that SS-Rail HRGCs have a higher incident frequency rate due to the driver having to consider both an HRGC and an intersection. Although, in this study, the eye-tracking results showed that participants mostly looked around the railroad track area. Still, SS-Rail HRGCs have a need for unique design considerations.

There are more cognitive challenges at an SS-Rail HRGC. There are also more Decision Points at this type of HRGC. Driver safety can be improved by limiting the complexity of the SS-Rail HRBC, and the decisions that need to made at them.

There are several limitations to this research. As this was the first lab experiment involving decisions related to SS-Rail HRGC images, research is needed to replicate the current findings and examine other factors that may affect safety concerns (e.g. balance of rail-related and non-rail-related objects in images).

This experiment focused on Decision Points $1 \& 2$ due to the nature of the images of the HRGCs; therefore, Decision Point 3 was harder to tell from the data we received. Future experiments may want to incorporate images at different viewpoints (some closer to the railroad tracks, some further away) to examine safety concerns and attention at Decision Point 3, and possibly even Decision Point 4. This would contribute to the generalizability of the current results.

Due to potential task fatigue, participants were only asked to annotate 11 images, eight of which involved rail crossings. Therefore, participants may have been sensitized toward HRGCs in this experiment. While this might have inflated the overall number of safety concerns, it would not be expected to affect the relative difference between the two HRGC types. However, future research could reduce the frequency of HRGCs in the images in any replication of this work.

Future directions of the research is the focus of the next chapter. However, next steps in this experiment involve further analyses of the eye-movement data and new laboratory experiments. For example, there were many objects in the tracks and warning area; future eye-tracking analyses will identify which objects (rail or non-rail) drivers were examining related to safety concerns. A future study may also compare the details of where urban and rural drivers are gazing, even though overall there were no differences in gaze behavior. 
Further lab studies might be done using different perspectives/angles of HRGCs. A future study might include all four of the Decision Points to evaluate if there are differences in what drivers pay attention to at different vantage points. Overall this experiment provides an initial understanding of driver safety concerns at HRGCs that suggested that they differ in cognitively interesting ways that impact railroad safety. 


\section{Conclusions}

Previous research has examined attention, behavior, and decision-making at HRGCs in general. This thesis extends that research by introducing a comparison between SS-Rail HRGCs, those with limited storage space after the tracks, to Non-SS-Rail HRGCs. Overall, across these two studies we found that drivers behave differently and notice different things at SS-Rail HRGCs compared to Non-SS-Rail HRGCs.

In the lab experiment, we found that not only did drivers have more safety concerns at SS-Rail HRGCS, but they rated them as more severe. Content analyses indicated that the SS-Rail safety concerns were differed from Non-SS-Rail in terms of dynamic rail related content, but not in terms of static information (e.g. signage).

Furthermore, eye-tracking results showed that participants overwhelmingly fixated on the general area of the tracks and warning and that rural drivers had shorter gaze durations than urban drivers.

\subsection{Future Research}

Approaching this cognitive obstacle course by using human strengths and limiting situations that exploit human weaknesses might ameliorate the cognitive challenges. Our studies confirmed Lundqvist and Eriksson's (2019) findings that older individuals suffer in their driving capabilities due to a higher cognitive load. We found that drivers over the age of 60 had a higher level of injury severity at SS-Rail HRGCs. This might be attributed to the even higher cognitive load of an SS-Rail HRGC. Future studies might explore older drivers encountering SS-Rail HRGCs. The Safety Concerns study had younger drivers as participants. Perhaps a future study might widen the age range to see if older drivers notice different safety concerns. Indeed, in the FRA study, we found differences with older drivers. It is possible that the same might be true for the Safety Concerns study.

Galpin et al., (2009) found that change blindness could lead to unsafe behavior with drivers. At an SS-Rail HRGC, drivers must be aware of the railroad track and look for a possible train. In addition, they must be aware of the upcoming intersection and gauge any changes occurring there. It is possible that a brief glance at the tracks might miss a change (such as a traffic light color change), which could lead to an incident. A driver must maintain attention and memory of integral parts of the SS-Rail while looking back and forth between the railroad tracks and the intersection. A future study might explore this further to see if things are being missed due to the need to go back and forth between the tracks and the intersection. 
According to Metz et all, (2011), collisions are linked with an inadequate distribution of attention during some type of distraction. The studies in this thesis suggest that the extra cognitive load of an SS-Rail could lead to distraction in itself. A vehicle going into a turn lane in front of another vehicle might be just enough distraction for the vehicle's driver to miss the barrier gate coming down signalling an arriving train. The next study in this vein might be to see what effect various distractions have on drivers in an SS-Rail HRGC.

Future research might be done in a simulator, using the findings provided herein. A simulated traversal look at the situation from the four Decision Points. Perhaps there are events that occur in Decision Points $1 \& 2$ that trigger outcomes at Decision Point 3. Perhaps there's a reason that more vehicles are stopped on the tracks at SS-Rail HRGCs, but moving over the tracks at Non-SS-Rail HRGCs. A study in a simulator can investigate these further by programming specific events in traversals. Eye-tracking might also complement simulator studies. Knowing where drivers are looked while reviewing driving scene images was informative, but they might have different scanpaths in a simulated environment.

Future analysis of our data will provide a richer set of eye-tracking results. For example, we know that most fixations were in the track area of the driving scenes. However, a further analysis might hone in on specific spaces at which drivers were looking. While in the track area, drivers may have been looking in the vertical center of this image where other vehicles were, or they may have been looking on the right side, where most of the signage is, and where a train might be approaching. Further analysis will reveal such results.

We learned that at SS-Rail HRGCs, vehicles are more likely to be stopped on the tracks. A future study might examine the factors that cause the vehicle to be stopped on the tracks. It may be that the cue is too long for the storage space, and a driver gets stopped on the tracks. Or perhaps, it may be that the driver is not paying attention to the cue, because they are focusing more on the HRGC factors. Furthermore, in a situation where there is not room in the storage space, is the driver intentionally trying to cross the tracks and squeeze into the storage space, or is this an unintentional act where the driver didn't notice the full storage space? These questions might be explored by interviewing drivers who have been stopped on the tracks about their experiences. Or perhaps a lab study might ask drivers to imagine they were in that situation and ask for possible reasons. 
As mentioned earlier, SS-Rail HRGCs presents drivers with a more cognitively challenging situation as was laid out in Chapter 1 because of added information processing at four different decision points. At Decision point 1, drivers must attend to the railroad warning systems and examine the signage that will be telling them what type of HRGCS is coming up. The SS-Rail sign adds yet another sign at this decision point, to which the driver need pay attention. In an already complex situation environment, this is an additional sign to scan and understand. For the SS-Rail HRGC the additional load is due to the additional signs and to potentially scanning forward to determine if there is an intersection after the railroad track. If there is, to plan accordingly. Drivers at Decision point 1 may notice the traffic light, and other drivers. At Decision Point 2, drivers must maintain awareness of the railroad track and any arriving trains. At decision point 3, drivers must determine if there is enough space to cross the track and get through the intersection.

Future studies might vary where the driver is in the Decision Points. As a case in point, study two evaluated drivers' safety concerns at Decision Points $1 \& 2$; however, because of the images that were selected, Decision Point 3 was not included in the driving scenes. A future study might include all 4 Decision Points in driving scene images.

This study used some crossings that came from the NDS study (Lautala, et al., 2018); the current experiment may provide information for future naturalistic driving studies. For example, future research could examine the rate of SS-Rail HRGCs in a naturalistic driving setting and code videos from these crossings to further investigate and potentially compare driver attention and decision behavior. The NDS study would focus on traversals without incidents or accidents and therefore complement the FRA analysis.

There are several limitations in this preliminary work. Regarding the FRA study, we were only able to interpret the FRA reports as provided online. There is some missing information, with some scant narratives that sometimes only restate information already provided. Although a good starting point, more information would be helpful. Police reports might be obtained to enhance the data and glean more information. Additionally, we were only able to learn the facts as stated. We were unable to learn about the cognitive events occurring with the drivers as these incidents happened. Lastly, we were only able to examine what occurred when there was an incident. There were many safe traversals over the SS-Rail HRGCs where drivers did not have incidents. We were unable to examine those instances. 


\subsection{Training Interventions}

More research is needed; however, these results have some preliminary implications for training. Training drivers in hazard perception has been successful (McDonald et al., 2015; Underwood, 2007). Experience, too, can improve hazard perception (Horswill and McKenna, 2004). Perhaps a driver training program can address SS-Rail HRGCs. For example, there are relevant objects at an SS-Rail HRGC - the tracks where there might be an arriving train, the traffic surrounding the driver, the intersection, traffic light, and of course the storage space. A training program might address the objects on which a driver should focus, or maybe how to maintain current information on both the intersection and the tracks.

\subsection{Decision Points}

The four decision points previously discussed might be the subject of a training program. Decision Point 1 is the point at which the first signage is seen for the railroad crossing and the SS-Rail facet of the crossing.

Drivers might be trained to have an efficient scanpath. For example, instead of just randomly going back and forth between the railroad, intersection, and traffic, their scanpath might be more economical if they focus on relevant objects in the railroad, intersection, and traffic. Respectively, they might be trained to focus on the active warning devices (gates, flashing lights), traffic light, amount of space being left between the tracks and the intersection.

In these studies, we attempted to evaluate driver's decisions at Decision Points $1,2, \& 3$, with varying levels of success. A future study might delve deeper into each Decision Point by examining where a driver's attention is, the decisions they are making, and their behavior at the various points.

\subsection{Environment interventions}

There are several environmental interventions to be considered. One intervention might be to decrease the cognitive load at SS-Rail HRGCs. Consider the signage alone - there is a sign indicating that there is an upcoming railroad, a sign indicating that the crossing is short-storage, a crossbuck at the tracks, a sign indicating how many sets of tracks there are, a traffic light, a sign indicating the lane configuration. Add to these signs, other drivers, each with their own maneuvers, and cross-traffic. It is no wonder that older drivers with naturally compromised cognitive processes have a higher incident rate at SSRails! 
One intervention to address this might be environmental - decluttering the area around the crossing. This might be addressed twofold. First, there are extra objects, such as advertisements and other non-traffic related objects. One remedy might be setting regulations on non-traffic object placement near or in the vicinity of an SS-Rail (or any railroad crossing for that matter). Alternatively, more economical traffic sign placement may reduce cognitive load while not negatively impacting safety. Generally, within 25 feet, one might come across the following signage: upcoming SS-Rail HRGC, upcoming traffic light, crossbuck, a sign stating the number of tracks, lane configuration signs. Perhaps the signage could be minimized.

If we learn in these future studies that people are paying attention to the signs or trying to pay attention to the signs, but have trouble, it may suggest a redesign of SS-Rail signs. The standard SS-Rail sign is black on a yellow background, the same as other warning signs. If the sign is buried amongst a sea of other signs, it may not be salient enough to stand out (McCarley et al., 2014).

Together these studies have ruled out a few factors. Further research might delve deeper into the Decision Points summarized above. Together, our studies have demonstrated that SS-Rail HRGCCs are approached differently by drivers. Driver's attention, behavior and decision-making are different at this type of crossing. As such, interventions should be approached differently. This work represents the beginning of a new line of research, there is still much to be learned. 


\section{Reference List}

Accidents that Shouldn't Happen, A. (1996). A Report of the Grade Crossing Safety Task Force to Secretary Federico Pena.

Agrawal, R., Knodler, M., Fisher, D.L., \& Samuel, S. (2017, September). Advanced virtual reality based training to improve young drivers' latent hazard anticipation ability. In Proceedings of the Human Factors and Ergonomics Society Annual Meeting (Vol. 61, No. 1, pp. 1995-1999). Sage CA: Los Angeles, CA: SAGE Publications.

Ambros, J., Perůtka, J., Skládaný, P., \& Tučka, P. (2019). Enhancing the insight into Czech railway level crossings' safety performance. International Journal of Rail Transportation, 1-10.

Babić, D., Babić, D., \& Ščukanec, A. (2017). The Impact of Road Familiarity on the Perception

of Traffic Signs-Eye Tracking Case Study. In Environmental Engineering. Proceedings of the International Conference on Environmental Engineering. ICEE (Vol. 10, pp. 1-

7). Vilnius Gediminas Technical University, Department of Construction Economics \& Property.

Beanland, V., Fitzharris, M., Young, K.L., \& Lenné, M.G. (2013). Driver inattention and driver distraction in serious casualty crashes: Data from the Australian National Crash In-depth Study. Accident Analysis \& Prevention, 54, 99-107.

Berg, W.D., Knoblauch, K., \& Hucke, W. (1982). Causal factors in railroad-highway grade crossing accidents (No. HS-033 767).

Brown, B. (2017). Evidence stacks up in favor of self-driving cars in 2016 NHTSA fatality report. Digital Trends. (https:/www.digitaltrends.com/cars/2016-nhtsa-fatalityreport/).

Campbell, R., Hollingsworth, J., \& Jackson, N. (2015). Stopped on the Tracks... And No Place to Go. Institute of Transportation Engineers. ITE Journal, 85(11), 26.

Catherine, B., Claudine, N., \& Daniel, M. (2000, July). Environmental cues involved in the visual anticipation of a collision. In Proceedings of the Human Factors and Ergonomics Society Annual Meeting (Vol. 44, No. 20, pp. 3-332). Sage CA: Los Angeles, CA: SAGE Publications.

Chan, E., Pradhan, A.K., Pollatsek, A., Knodler, M.A., \& Fisher, D.L. (2010). Are driving simulators effective tools for evaluating novice drivers' hazard anticipation, speed management, and attention maintenance skills?. Transportation research part F: traffic psychology and behaviour, 13(5), 343-353. 
Chapman, P.R., \& Underwood, G. (1998). Visual search of driving situations: Danger and experience. Perception, 27(8), 951-964.

Cho, H., \& Rilett, L.R. (2007). Improved transition preemption strategy for signalized intersections near at-grade railway grade crossing. Journal of transportation engineering, 133(8), 443-454.

Cooper, D.L., \& Ragland, D.R. (2008). Addressing Inappropriate Driver Behavior at Rail-Highway Crossings. Institute of Transportation Studies, UC Berkeley, Institute of Transportation Studies, Research Reports, Working Papers, Proceedings.

Courage, C., Milgram, P., \& Smiley, A. (2000, July). An investigation of attentional demand in a simulated driving environment. In Proceedings of the Human Factors and Ergonomics Society Annual Meeting (Vol. 44, No. 20, pp. 3-336). Sage CA: Los Angeles, CA: SAGE Publications.

Di Nocera, F., Camilli, M., \& Terenzi, M. (2006, October). Using the distribution of eye fixations to assess pilots' mental workload. In Proceedings of the Human Factors and Ergonomics Society Annual Meeting (Vol. 50, No. 1, pp. 63-65). Sage CA: Los Angeles, CA: SAGE Publications.

Eluru, N., Bagheri, M., Miranda-Moreno, L.F., \& Fu, L. (2012). A latent class modeling approach for identifying vehicle driver injury severity factors at highway-railway crossings. Accident Analysis \& Prevention, 47, 119-127.

Endsley, M. (1995). Endsley, M.R.: Toward a Theory of Situation Awareness in Dynamic Systems. Human Factors Journal 37(1), 32-64. Human Factors: The Journal of the Human Factors and Ergonomics Society. 37. 32-64. 10.1518/001872095779049543.

FRA. (2016). Highway-Rail Crossing \& Trespassing Fact Sheet. https://railroads.dot.gov/sites/fra.dot.gov/files/docs/newsroom/186/rrx-fact-sheetfinal12716.pdf

Galpin, A., Underwood, G., \& Crundall, D. (2009). Change blindness in driving scenes. Transportation research part F: traffic psychology and behaviour, 12(2), 179-185.

Haleem, K., \& Gan, A. (2015). Contributing factors of crash injury severity at public highway-railroad grade crossings in the US. Journal of safety research, 53, 23-29.

Hankey, J.M., Perez, M.A., \& McClafferty, J.A. (2016). Description of the SHRP 2 naturalistic database and the crash, near-crash, and baseline data sets. Virginia Tech Transportation Institute. 
Hao, W., \& Daniel, J. (2014). Motor vehicle driver injury severity study under various traffic control at highway-rail grade crossings in the United States. Journal of safety research, 51, 41-48.

Highway-Rail Incidents. Federal Railroad Administration. Retrieved on March 5, 2020 from https://safetydata.fra.dot.gov/OfficeofSafety/publicsite/query/gxrtally1.aspx

Hoel, J., Jaffard, M., Van Elslande, P., 2010. Attentional competition between tasks and its implications. Paper presented at the European Conference on Human Centred Design for Intelligent Transport Systems (29-30 April). Retrieved from http://www.conference2010.humanist-vce.eu/.

Horrey, W.J., Lesch, M.F., Mitsopoulos-Rubens, E., \& Lee, J.D. (2015). Calibration of skill and judgment in driving: Development of a conceptual framework and the implications for road safety. Accident Analysis \& Prevention, 76, 25-33.

Horswill, M.S., \& McKenna, F.P. (2004). Drivers' hazard perception ability: Situation awareness on the road. In S. Banbury \& S. Tremblay (Eds.). A Cognitive Approach to Situation Awareness (pp.155-175). Aldershot, UK: Ashgate.

Huestegge, L., Skottke, E.M., Anders, S., Müsseler, J., \& Debus, G. (2010). The development of hazard perception: Dissociation of visual orientation and hazard processing. Transportation Research Part F: Traffic Psychology and Behaviour, 13(1), 1-8.

Indiana.gov. (2011). https://www.in.gov/dot/div/contracts/standards/dm/2011/Part5/Ch42/Ch42.pdf

Kim, H., Gabbard, J.L., Martin, S., Tawari, A., \& Misu, T. (2019, November). Toward Prediction of Driver Awareness of Automotive Hazards: Driving-Video-Based Simulation Approach. In Proceedings of the Human Factors and Ergonomics Society Annual Meeting (Vol. 63, No. 1, pp. 2099-2103). Sage CA: Los Angeles, CA: SAGE Publications.

Landry, S. (2016). Getting Active with passive crossings: investigating the efficacy of invehicle auditory alerts for rail road crossings. [Master's thesis, Michigan Technological University]. digitalcommons.mtu.edu.

Landry, S., Jeon, M., Lautala, P., \& Nelson, D. (2019). Design and assessment of invehicle auditory alerts for highway-rail grade crossings. Transportation research part F: traffic psychology and behaviour, 62, 228-245. 
Lautala, P, Jeon, M, Nelson, D, Landry, S, Dean, A. (2018). Driver Behavior at Highway-Rail Grade Crossings Using NDS and Driving Simulators. Federal Railroad Administration, Report No. FRA/OMB No. 0704-0188.

Leibowitz, H.W. (1985). Grade Crossing Accidents and Human Factors Engineering: How a discipline combining technology and behavioral science can help reduce traffic fatalities. American Scientist, 73(6), 558-562.

Lenné, M.G., Mitsopoulos-Rubens, E., Candappa, N., \& Beanland, V. (2014, September). Drivers' response to dynamic gap assistance signs at simulated rural unsignalised T-intersections. In Proceedings of the Human Factors and Ergonomics Society Annual Meeting (pp. 2240-2244). Los Angeles, CA: SAGE.

Lenné, M.G., Rudin-Brown, C.M., Navarro, J., Edquist, J., Trotter, M., \& Tomasevic, N. (2011). Driver behaviour at rail level crossings: Responses to flashing lights, traffic signals and stop signs in simulated rural driving. Applied ergonomics, 42(4), 548554.

Lenne, M.G., Salmon, P.M., \& Young, K.L. (2011). An exploratory study assessing driver behaviour at highway-rail grade crossing using on-road test vehicles. In 3rd International Conference on Road Safety and Simulation.

Lerner, N., Baldwin, C., Higgins, J.S., Lee, J., \& Schooler, J. (2015, September). Mind wandering while driving: What does it mean and what do we do about it?. In Proceedings of the human factors and ergonomics society annual meeting (Vol. 59, No. 1, pp. 1686-1690). Sage CA: Los Angeles, CA: SAGE Publications.

Lerner, N.D., Ratte, D., \& Walker, J. (1990). Driver behavior at rail-highway crossings. US Department of Transportation.

Linja, A., Lautala, P., Nelson, D., Veinott, E. (2020). Rail Safety: Examining the Effect of Driving Experience and Type of Crossing on Safety Concerns. Poster presented at the Human Factors and Ergonomics Society Annual Meeting, October, 2020 in Chicago, IL.

Liu, J., \& Khattak, A.J. (2017). Gate-violation behavior at highway-rail grade crossings and the consequences: using geo-spatial modeling integrated with path analysis. Accident Analysis \& Prevention, 109, 99-112.

Liu, J., Khattak, A. J., Richards, S.H., \& Nambisan, S. (2015). What are the differences in driver injury outcomes at highway-rail grade crossings? Untangling the role of precrash behaviors. Accident Analysis \& Prevention, 85, 157-169. 
Lundqvist, L.M., \& Eriksson, L. (2019). Age, cognitive load, and multimodal effects on driver response to directional warning. Applied ergonomics, 76, 147-154.

Marshall, P.S., \& Berg, W.D. (1997). Design guidelines for railroad preemption at signalized intersections. ITE journal, 67(2).

McCarley, J.S., Steelman, K.S., \& Horrey, W.J. (2014). The View from the Driver's Seat: What Good Is Salience?. Applied cognitive psychology, 28(1), 47-54.

McDonald, C.C., Goodwin, A.H., Pradhan, A.K., Romoser, M.R., \& Williams, A.F. (2015). A review of hazard anticipation training programs for young drivers. Journal of Adolescent Health, 57(1), S15-S23.

McKenna, F.P., \& Crick, J.L. (1994). Hazard perception in drivers: A methodology for testing and training. TRL contractor report, (313).

Meeker, F., Fox, D., \& Weber, C. (1997). A comparison of driver behavior at railroad grade crossings with two different protection systems. Accident Analysis \& Prevention, 29(1), 11-16.

Metz, B., Schömig, N., \& Krüger, H.P. (2011). Attention during visual secondary tasks in driving: Adaptation to the demands of the driving task. Transportation research part F: traffic psychology and behaviour, 14(5), 369-380.

Millegan, Hal, PHD, P.E., Yan, X., Stephen Richards PHD, P. E., \& Han, L. D. (2010). Do stop signs improve safety at highway-railroad grade crossings?. Institute of Transportation Engineers. ITE Journal, 80(2), 18.

Mueller, S.T., \& Piper, B.J. (2014). The psychology experiment building language (PEBL) and PEBL test batter. Journal of neuroscience methods, 222,250-259.

Muhire, M., Lautala, P., Nelson, D., \& Dean, A. (2017). Selection of Representative Crossings Database for the Evaluation of Driver Behavior Over Highway-Rail Grade Crossings. In 2017 Joint Rail Conference. American Society of Mechanical Engineers Digital Collection.

Ogden, B.D., \& Cooper, C. (2019). Highway-Rail Crossing Handbook (No. FHWA-SA18-040). United States. Federal Highway Administration.

Oh, J., Washington, S.P., \& Nam, D. (2006). Accident prediction model for railwayhighway interfaces. Accident Analysis \& Prevention, 38(2), 346-356.

Operation Lifesaver. (n.d.). https://oli.org/ 
Pelz, D.C., \& Krupat, E. (1974). Caution profile and driving record of undergraduate males. Accident Analysis \& Prevention, 6(1), 45-58.

Pennetti, C.A., Hollenback, K., Kim, I., \& Lambert, J.H. (2019, November). Cognitive Load Variability from Road Characteristics Should Influence a Safety Requirement for Vehicle Stopping Sight Distance. In Proceedings of the Human Factors and Ergonomics Society Annual Meeting (Vol. 63, No. 1, pp. 2129-2133). Sage CA: Los Angeles, CA: SAGE Publications.

Raub, R.A. (2009). Examination of highway-rail grade crossing collisions nationally from 1998 to 2007. Transportation research record, 2122(1), 63-71.

Read, G.J.M., Clacy, A., Thomas, M., Van Mulken, M.R.H., Stevens, N., Lenne, M.G., ... \& Salmon, P.M. (2016, September). Evaluation of novel urban rail level crossing designs using driving simulation. In Proceedings of the Human Factors and Ergonomics Society Annual Meeting (Vol. 60, No. 1, pp. 1921-1925). Sage CA: Los Angeles, CA: SAGE Publications.

Recarte, M.A., \& Nunes, L.M. (2000). Effects of verbal and spatial-imagery tasks on eye fixations while driving. Journal of experimental psychology: Applied, 6(1), 31.

Regan, M.A., Hallett, C., \& Gordon, C. P. (2011). Driver distraction and driver inattention: Definition, relationship and taxonomy. Accident Analysis \& Prevention, 43(5), 1771-1781.

Rensink, R.A., Kevin O'Regan, J., \& Clark, J. J. (2000). On the failure to detect changes in scenes across brief interruptions. Visual cognition, 7(1-3), 127-145.

Richards, S.H., \& Heathington, K.W. (1990). Assessment of warning time needs at railroad-highway grade crossings with active traffic control. Transportation Research Record, 1254, 72-84.

Salim, A. (2018). Evaluation of Driver Behavior at Highway-Railroad Grade Crossings Based on Environmental Conditions and Driver Demographics. [Unpublished master's thesis]. Michigan Technological University.

Salim, A., Jeon, M., Lautala, P., \& Nelson, D. (2018, April). Using Naturalistic Driving Study Data to Investigate Driver Behavior at Highway-Rail Grade Crossings. In 2018 Joint Rail Conference. American Society of Mechanical Engineers Digital Collection.

Salmon, P.M., Lenné, M.G., Young, K.L., \& Walker, G.H. (2013). An on-road network analysis-based approach to studying driver situation awareness at rail level crossings. Accident Analysis \& Prevention, 58, 195-205. 
Sanders, J.H., Kolsrud, G.S., \& Berger, W.G. (1973). Human factors countermeasures to improve highway-railway intersection safety (No. DOT HS-800 888). United States. National Highway Traffic Safety Administration.

Tey, L.S., Wallis, G., Cloete, S., \& Ferreira, L. (2013). Modelling driver behaviour towards innovative warning devices at railway level crossings. Accident Analysis \& Prevention, 51, 104-111.

The Strategic Highway Research Program 2 Transportation Research Board of The National Academies. (2002). Description of the SHRP 2 Naturalistic Database and the Crash, Near-Crash and Baseline Data Sets Task Report. https://vtechworks.lib.vt.edu/bitstream/handle/10919/70850/SHRP_2_CrashNearCras hBaselineReport_4-25-16.pdf

Tidwell Jr, J.E., \& Humphreys, J.B. (1981). Improving Safety at Passive Crossings with Restricted Sight Distance. Transportation Research Record, 841, 36.

Tustin, B.H., Richards, H., McGee, H., \& Patterson, R. (1986). Railroad-highway grade crossing handbook (No. FHWA-TS-86-215). United States. Federal Highway Administration.

Underwood, G. (2007). Visual attention and the transition from novice to advanced driver. Ergonomics, 50(8), 1235-1249.

Underwood, G., Chapman, P., Brocklehurst, N., Underwood, J., \& Crundall, D. (2003). Visual attention while driving: sequences of eye fixations made by experienced and novice drivers. Ergonomics, 46(6), 629-646.

Unverricht, J., Yamani, Y., Yahoodik, S., Chen, J., \& Horrey, W.J. (2019, November). Attention maintenance training: Are young drivers getting better or being more strategic?. In Proceedings of the Human Factors and Ergonomics Society Annual Meeting (Vol. 63, No. 1, pp. 1991-1995). Sage CA: Los Angeles, CA: SAGE Publications.

Ward, N.J., \& Wilde, G.J. (1996). Driver approach behaviour at an unprotected railway crossing before and after enhancement of lateral sight distances: an experimental investigation of a risk perception and behavioural compensation hypothesis. Safety Science, 22(1-3), 63-75. 
Witte, K., \& Donohue, W.A. (2000). Preventing vehicle crashes with trains at grade crossings: the risk seeker challenge. Accident Analysis \& Prevention, 32(1), 127-139.

Yeh, M., Raslear, T., \& Multer, J. (2012, September). Evaluating the impact of grade crossing safety factors through signal detection theory. In Proceedings of the Human Factors and Ergonomics Society Annual Meeting (Vol. 56, No. 1, pp. 2226-2230). Sage CA: Los Angeles, CA: SAGE Publications.

Young, K.L., Lenné, M.G., Salmon, P.M., \& Stanton, N.A. (2018). The impact of texting on driver behaviour at rail level crossings. Accident Analysis \& Prevention, $118,269-276$.

Young, M.S., \& Stanton, N.A. (2002). Malleable attentional resources theory: a new explanation for the effects of mental underload on performance. Human factors, 44(3), 365-375.

Zhao, S., \& Khattak, A. J. (2017). Factors associated with self-reported inattentive driving at highway-rail grade crossings. Accident Analysis \& Prevention, 109, 113122.

Zhao, S., \& Khattak, A. J. (2018). Injury severity in crashes reported in proximity of rail crossings: The role of driver inattention. Journal of Transportation Safety \& Security, 10(6), 507-524.

Zimmerman, L.A., Mueller, S.T., Marcon, J.L., Daniels, J.B., \& Vowels, C.L. (2011). Improving soldier threat detection skills in the operational environment. In Interservice/ Industry Training, Simulation, and Education Conference (IITSEC) (pp. 1-12. Orlando: Florida: IITSEC. 


\section{Appendix}

\section{A1 Fields extracted for FRA Database study}

\section{Incident Information:}

$\circ \quad$ FRA Incident Year

○ Incident \# (6180-57 online)

$\circ \quad \mathrm{Kld} / \mathrm{Inj}$ (total injured killed)

○ Incident Date (6180-57 online)-5

- Rail Equip (6180-57 online)-24 (train type)

○ Consist Length (6180-57 online)-28+29

○ Total Kld (6180-57 online)-46/49/52

○ Total Inj (6180-57 online)-46/49/52

- Consistent Speed (6180-57 pdf-30) (of train)

○ Time Table Dir (6180-57 pdf-31)

○ narrative (6180-57 pdf-54)

○ Motorist (6180-57 online)-41 (motorist action/inaction: Did not stop, went through gate, etc.)

○ Position (6180-57 online)-16 (motorist position upon impact: Moving over crossing, Stopped on crossing, etc.)

$\circ \quad 5 \mathrm{k}$ location(55) (e.g., yard, repair shop, etc. plus involved rail equip plus person's location related to above)

○ $\quad 51$ event (55) (e.g., collision/impact, caught between equipment, etc.)

$\circ \quad 5 n$ cause $(55)$

$\circ \quad 5$ u narrative $(55)$

\section{Motor Veh. Driver Information:}

○ Highway User (6180-57 online)-13 (motor vehicle type)

○ Vehicle Speed (6180-57 pdf-14)

- Vehicle Direction (6180-57 pdf-15)

○ Circumstance (6180-57 pdf-19) 1. Rail equipment struck highway user 2. Rail equipment struck by highway user

$\circ \quad$ veh age (6180-57 pdf38) (motorist age)

$\circ \quad$ veh gender (6180-57 pdf-39) (motorist gender)

$\circ \quad$ driver (6180-57 pdf-44) (1. Killed 2. Injured 3. Uninjured)

○ \# veh occ (6180-57 pdf-48) (number of vehicle occupants) 
$\circ \quad 5$ h-drug/alc (55) (testing done?)

- $\quad 5 \mathrm{i}$ inj code (55) (injury condition being reported)

$\circ \quad 5 \mathrm{j}$ phys act(55) ((What was the person doing when hurt?)

\section{Environment information:}

- $\quad$ Visibility (6180-57 pdf-22)

- road conditions (6180-57 pdf-34)

$\circ \quad$ illumination (6180-57 pdf-37)

\section{Railroad information:}

- Crossing ID (6180-71 online)

- Cross Prot (6180-57 online)

$\circ \quad$ Type xing Warning (6180-57 pdf-32)

$\circ \quad$ xing warning (6180-57 pdf-33)

$\circ \quad$ warning loc (6180-57 pdf-35)

- hwy? (6180-57 pdf-36)

- obstr (6180-57 pdf-43)

- 5s latitude (55)

$\circ \quad 5 t$ longitude (55)

- Crossbuck \# (2a inventory)

$\circ \quad$ Stop (2b inventory)

- Yield (2c inventory)

- 3C Cantilevered (or Bridged) Flashing Light Structures (count)

- 3D Mast Mounted Flashing Lights (count of masts)

- 3E Total Count of Flashing Light Pairs

- Gates (inventory 3i)

- Hwy Traffic Signal (inv sec III, 4A)

- Preemption (inv sec III, 4C)

- Satellite Image Date_Gogle Earth data

- Short Storage_Gogle Earth data

- Anne-SS Feet for FRA Incident

- Distance from intersection (ft, dir)_Gogle Earth data

- Quadrant Blocked_1_Gogle Earth data

- Quadrant Blocked_2_Gogle Earth data

- Quadrant Blocked_3_Gogle Earth data

- Quadrant Blocked_4_Gogle Earth data

- Type of protection_Gogle Earth data 
○ Crossbuck_Gogle Earth data

- Stop sign_Gogle Earth data

- Yield sign_Gogle Earth data

- Lights_Gogle Earth data

- Gates_Gogle Earth data

- Bells_Gogle Earth data

o Notes_Gogle Earth data 


\section{A2 Experiment 2 Questionnaire}

Here are the questions in the questionnaire:

1. What is your gender?

2. How old are you?

3. How many years have you been driving?

4. Considering the past 6 months, in a typical week, how many hours might you drive?

5. If you're not from the U.P., in what cities or suburbs have you driven extensively? (Please enter "City, State" for each city).

6. During the summer, how many railroad crossings do you pass through per month, on average?

7. In general how dangerous do you find railroad crossings typically?

For the last set of questions, participants were given a knowledge test on road signs:

8. - 12. What are you supposed to do when you see the following visual warning sign?

\begin{tabular}{|l|l|}
\hline Sign & Correct Answer \\
\hline Railroad tracks ahead \\
\hline
\end{tabular}




Crossbuck Sign




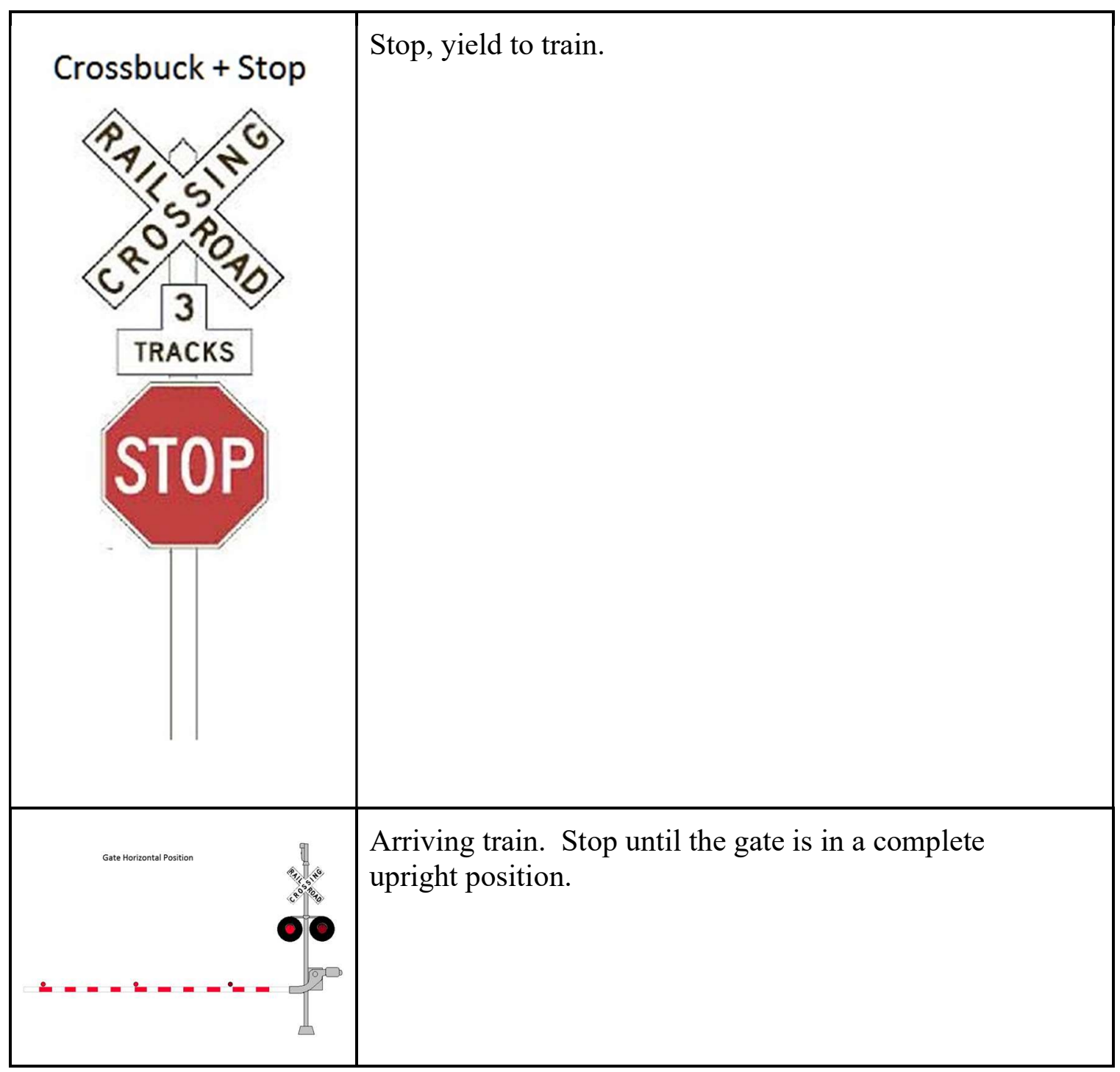




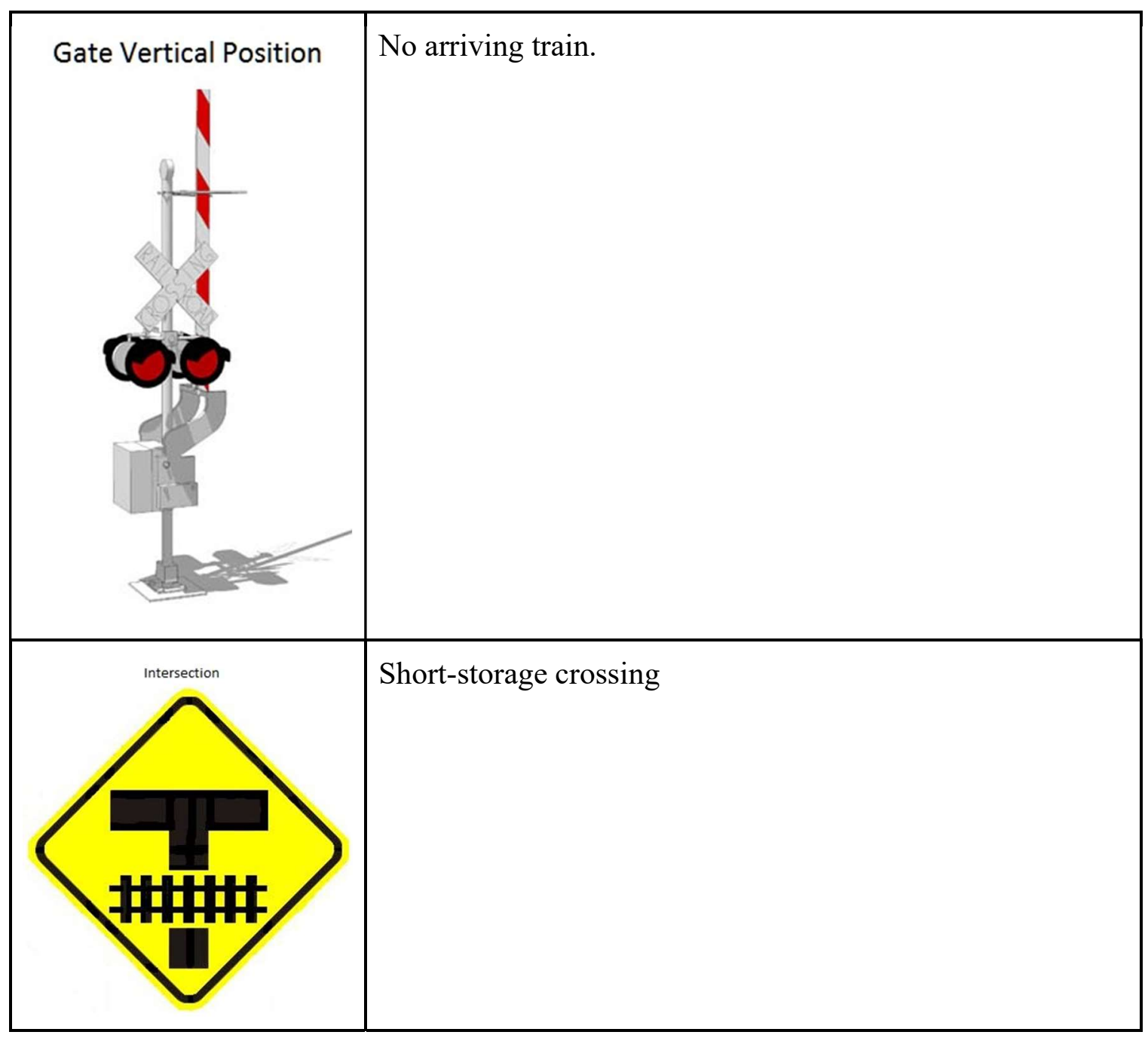




\section{Copyright documentation}

All images in this document are from Google Images.

4: "Railroad Sign". https://driving-tests.org/road-signs/railroad-crossing-sign/

Figure 1.5: "Short-Storage Railroad Ahead".

https://mutcd.fhwa.dot.gov/services/publications/fhwaop02084/images/w10_11.jpg

Figure 1.6: "Crossbuck Sign".

https://www.safetysupplywarehouse.com/CROSSBUCK_RAILROAD_CROSSING

Sign $\mathrm{p} / \mathrm{w} 14334 . \mathrm{htm}$

Appendix 2:

"Railroad Sign". https://www.etsy.com/ie/listing/658215665/railroad-

crossing-sign-train-warning-1

"Crossbuck Sign". https://www.cleanpng.com/png-rail-transport-level-

crossing-train-crossbuck-sign-890924/preview.html

"Crossbuck with Yield Sign" \& "Crossbuck with Stop Sign. https://californiadmv-practice-test.org/what-does-the-crossbuck-sign-mean/

"Boom Barrier Gates". https://www.clipart.email/clipart/railroad-crossinggate-clipart-441769.html

Figure 1.6: "Crossbuck Sign".

https://www.safetysupplywarehouse.com/CROSSBUCK_RAILROAD_CRO

SSING_Sign_p/w14334.htm 